\title{
Seasonal Effects of Indian Ocean Freshwater Forcing in a Regional Coupled Model*
}

\author{
HYODAE SEO \\ International Pacific Research Center, University of Hawaii at Manoa, Honolulu, Hawaii \\ SHANG-PING XIE \\ International Pacific Research Center, and Department of Meteorology, University of Hawaii at Manoa, Honolulu, Hawaii \\ RAghu Murtugudde \\ Earth System Science Interdisciplinary Center, Department of Atmospheric and Oceanic Science, \\ University of Maryland, College Park, College Park, Maryland \\ MARKUS JOCHUM \\ National Center for Atmospheric Research, Boulder, Colorado \\ ARTHUR J. MiLLER \\ Scripps Institution of Oceanography, University of California, San Diego, La Jolla, California
}

(Manuscript received 16 December 2008, in final form 30 July 2009)

\begin{abstract}
Effects of freshwater forcing from river discharge into the Indian Ocean on oceanic vertical structure and the Indian monsoons are investigated using a fully coupled, high-resolution, regional climate model. The effect of river discharge is included in the model by restoring sea surface salinity (SSS) toward observations. The simulations with and without this effect in the coupled model reveal a highly seasonal influence of salinity and the barrier layer (BL) on oceanic vertical density stratification, which is in turn linked to changes in sea surface temperature (SST), surface winds, and precipitation.

During both boreal summer and winter, SSS relaxation leads to a more realistic spatial distribution of salinity and the BL in the model. In summer, the BL in the Bay of Bengal enhances the upper-ocean stratification and increases the SST near the river mouths where the freshwater forcing is largest. However, the warming is limited to the coastal ocean and the amplitude is not large enough to give a significant impact on monsoon rainfall.

The strengthened BL during boreal winter leads to a shallower mixed layer. Atmospheric heat flux forcing acting on a thin mixed layer results in an extensive reduction of SST over the northern Indian Ocean. Relatively suppressed mixing below the mixed layer warms the subsurface layer, leading to a temperature inversion. The cooling of the sea surface induces a large-scale adjustment in the winter atmosphere with amplified northeasterly winds. This impedes atmospheric convection north of the equator while facilitating it in the austral summer intertropical convergence zone, resulting in a hemispheric-asymmetric response pattern. Overall, the results suggest that freshwater forcing from the river discharges plays an important role during the boreal winter by affecting SST and the coupled ocean-atmosphere interaction, with potential impacts on the broadscale regional climate.
\end{abstract}

\footnotetext{
* International Pacific Research Center Publication Number 626 and School of Ocean and Earth Science and Technology Publication Number 7788 .
}

Corresponding author address: Hyodae Seo, International Pacific Research Center, University of Hawaii at Manoa, 1680 East-West Road, POST Bldg., \#401, Honolulu, HI 96822.

E-mail: hyodae@hawaii.edu 


\section{Introduction}

The Bay of Bengal (BoB) receives substantial freshwater flux from both local precipitation and river discharge during the summer southwest (SW) monsoon. Precipitation well exceeds evaporation (Harenduprakash and Mitra 1988; Prasad 1997). In addition, major rivers from the bordering countries-the Irrawaddy, the Krishna, the Godavari, the Mahanadi, the Ganges, and the Brahmaputra-discharge an annual freshwater volume into the $\mathrm{BoB}$, whose estimates vary between $1.5 \times 10^{12} \mathrm{~m}^{3}$ (Thadathil et al. 2002) and $1.83 \times 10^{13} \mathrm{~m}^{3}$ (Varkey et al. 1996), making the BoB the freshest region in the Indian Ocean. Seasonally, three-fourths of all riverine influx occurs during the SW monsoon period from May until September, indicating that this substantial summertime freshwater influx will affect the hydrography of the bay during the northeast (NE) monsoon (Shetye et al. 1996).

The unique summertime and wintertime oceanic conditions associated with the presence of a low-salinity layer lead to marked variations in density stratification and vertical mixing in the BoB both in summer (Vinayachandran et al. 2002) and winter (Shetye et al. 1996). The strong halocline associated with the surface freshwater cap shoals the density mixed layer (ML), while the isothermal layer depth (ILD) is usually deeper. Thus salinity has a crucial control on the depth to which mixing effects are confined. The ILD is defined in this study as the depth at which temperature drops from sea surface temperature (SST) by $\Delta T=1^{\circ} \mathrm{C}$. The ML depth (MLD) is defined as the depth at which the salinity effect on the density variation is equivalent to the variation of temperature by $\Delta T=1^{\circ} \mathrm{C}$ from the sea surface. Following the criterion of Sprintall and Tomczak (1992), the positive difference in the MLD and ILD is termed the barrier layer (BL) (Lukas and Lindstrom 1991) since it acts as a barrier to the mixing of cold thermocline water into the surface ML, essentially decoupling the dynamics and the thermodynamics. That is, the stratified BL retains atmospheric heat and momentum inputs predominantly within the ML while reducing the entrainment of the cooler thermocline water from the bottom (Vialard and Delecluse 1998). A survey of BL thickness (BLT) by Sprintall and Tomczak (1992) using the Levitus (1982) climatology indicates that BLs exist throughout the year in the BoB, with a thickness of $25 \mathrm{~m}$ during August-October in the northwestern part of the bay (Vinayachandran et al. 2002). Rao and Sivakumar (2003) also discuss the formation mechanism and seasonal cycle of the BL in the northern Indian Ocean. They showed that the build up of the BL during summertime becomes most prominent by February in the following year, reaching a maximum thickness of $50 \mathrm{~m}$.
The boreal winter is the period when the hydrological forcing generates its largest freshening effects through the river discharge and local rainfall. The BLT subsequently diminishes from February to a minimum in May before onset of the summer monsoon. Based on more recent datasets with better spatial and temporal coverage, various investigators confirm the seasonal cycle and observed thickness of the BL in the BoB and northern Indian Ocean (e.g., Thadathil et al. 2007; Mignot et al. 2007; de Boyer Montégut et al. 2007, hereafter DMLC07).

High SST in the BoB is conducive to deep convection in the atmosphere and hence precipitation during the SW monsoon season (Gadgil et al. 1984; Shenoi et al. 2002). Altered atmospheric convection results in variations in air-sea heat flux, which can further influence the convection itself via SST changes (Krishnamurti et al. 1988). Furthermore, through the aforementioned impact of the BL on ocean mixing, surface freshwater affects SST and ocean-atmosphere coupling (Vinayachandran et al. 2002). From the measurements of surface meteorological fields and near-surface salinity structure at the head of the bay during the Monsoon Trough Boundary Layer Experiment (MONTBLEX-90) field experiment during August-September 1990, Sanilkumar et al. (1994) showed that the low-salinity layer leads to the accumulation of heat in the upper $30 \mathrm{~m}$ of the ocean, which triggers the genesis and propagation of atmospheric moist convection and monsoon depressions. This is due to the nonlinearity and coupling of moisture, convection, and SST, enabling small variations in SST to affect atmospheric circulations and convection (Soman and Slingo 1997; Shankar et al. 2007; Zhou and Murtugudde 2009), with an important implication for the SW monsoon winds and rainfall over the northern Indian Ocean (Ueda et al. 2009).

The mechanism by which the BL influences the summertime stratification and ML temperature of the BoB is essentially the same in winter when the BL attains its maximum thickness (Thadathil et al. 2007). The effect of wintertime heat flux and the continental wind (Hastenrath and Lamb 1979) is retained within this shallow ML, while the subsurface layer is insulated from the surface cooling. The vertical temperature distribution of a cold surface and warmer subsurface layer leads to a temperature inversion (Shetye et al. 1996; Thadathil et al. 2002; DMLC07).

The wintertime low salinity water in the $\mathrm{BoB}$ is then advected by the winter monsoon current toward the southeast Arabian Sea (SEAS). This arrival of cold, less saline water over the warm saline Arabian Sea water is considered to contribute to the formation of the $\mathrm{BL}$ and an inversion layer (Lukas and Lindstrom 1991; Thadathil 
and Gosh 1992; Shenoi et al. 1999) and the so-called mini warm pool through the reduction of vertical mixing (Vialard and Delecluse 1998) in the Lakshadweep Sea during the presummer monsoon season (Joseph 1990; Rao and Sivakumar 1999; Vinayachandran et al. 2007). Kurian and Vinayachandran (2007) suggest from a series of experiments that low-wind conditions due to the orographic effects of the Western Ghats and the resultant reduced latent heat loss over the SEAS greatly contribute to the formation of the mini warm pool. Masson et al. (2005) showed that this BL and subsurface inversion in SEAS substantially contribute to the warming of SST during the premonsoon season and rainfall, facilitating the formation of the monsoon onset vortex and the early onset of the SW monsoon (Rao and Sivakumar 1999).

Barrier layers and the temperature inversion in the SEAS are good examples showing that oceanic processes can impact the characteristics of the Indian summer monsoon. However, it is not clear in the literature if, and how, the activity of the winter monsoon is affected by the BL. Recalling that BLs reach their maximum thickness during boreal winter, it is natural to ask whether this BL-SST-monsoon connection is at work in winter.

Answering such a question requires the use of numerical models that capture BL effects. However, a conclusive identification of the influence of a freshwater cap on SST and the Indian monsoon is difficult with ocean general circulation models (OGCMs), where a simple atmospheric boundary model has to be employed to compute surface heat and momentum flux (Vialard and Delecluse 1998; Han et al. 2001; Han and McCreary 2001; Masson et al. 2002; Durand et al. 2004). This simple approach limits the models' ability to evaluate the salinity effect on the SST owing to the lack of fully coupled heat and wind forcing. Murtugudde and Busalacchi (1998) and Howden and Murtugudde (2001, hereafter HM01) used an advective atmospheric mixed-layer model (Seager et al. 1995) that computes its own heat flux, but the wind is still imposed. Furthermore, the advective atmospheric mixed layer could be problematic over the BoB because the land temperatures are very different from SSTs.

Masson et al.'s (2005) study is probably the only one that used a fully coupled GCM (CGCM) to examine the effect of salinity stratification and the BL on the Indian monsoon. In their sensitivity experiment, the potential density was computed as a function of temperature alone in order to suppress the turbulent processes associated salinity stratification (Vialard and Delecluse 1998). In their model, however, there was no significant change in the monsoon over continental India due to the BL dynamics in the SEAS, while the effect of the $\mathrm{BL}$ is rather local to the region where the perturbation is added. This was attributed partly to the coarseresolution atmospheric model, which fails to capture the mature phase of the Indian monsoon and its extent over the continent.

The present study uses a higher-resolution regional coupled climate model with the goal of assessing climate sensitivity in the Indian Ocean sector to freshwater forcings and BLs. By allowing ocean-atmosphere interactions on relatively fine ocean and atmospheric grids, the regional coupled model could provide an assessment of the salinity effect on the SST and the monsoons by resolving more detailed structures of the coupled system. To this end, we perform two coupled experiments, with and without the effect that mimics the freshwater forcing from the river discharges, and demonstrate the sensitivity of the ocean, atmosphere, and the coupled system to freshwater forcing.

Briefly, our modeling results show that it is in boreal winter when the dynamics of the BL is most influential on the Indian monsoon. This is because BLs are thicker in winter when the surface heat flux more efficiently cools the thin ML and sea surface. Significant cooling of the ocean in turn induces a large-scale response in the boreal winter atmosphere by strengthening the winter monsoon wind and displacing the intertropical convergence zone (ITCZ) southward.

The paper is organized as follows. In section 2 , a description of the model and of the observational data is presented. Section 3 introduces the experimental design and validates the salinity fields. Various aspects of the model biases in the seasonal mean climate are discussed in section 4 . In section 5, we discuss the impact of low salinity on the oceanic vertical structure in summer and winter. Section 6 examines a link between SW and NE monsoons to the altered SSTs by sea surface salinity (SSS). Conclusions and discussion follow in section 7 .

\section{Model and observational data}

\section{a. Scripps Coupled Ocean-Atmosphere Regional model}

The coupled model used for the present study is the Scripps Coupled Ocean-Atmosphere Regional (SCOAR) model. Two regional models, the Experimental Climate Prediction Center (ECPC) Regional Spectral Model (RSM) (Juang and Kanamitsu 1994) for the atmosphere and the Regional Ocean Modeling System (ROMS) (Haidvogel et al. 2000; Shchepetkin and McWilliams 2005) for the ocean, are coupled through a flux-SST 

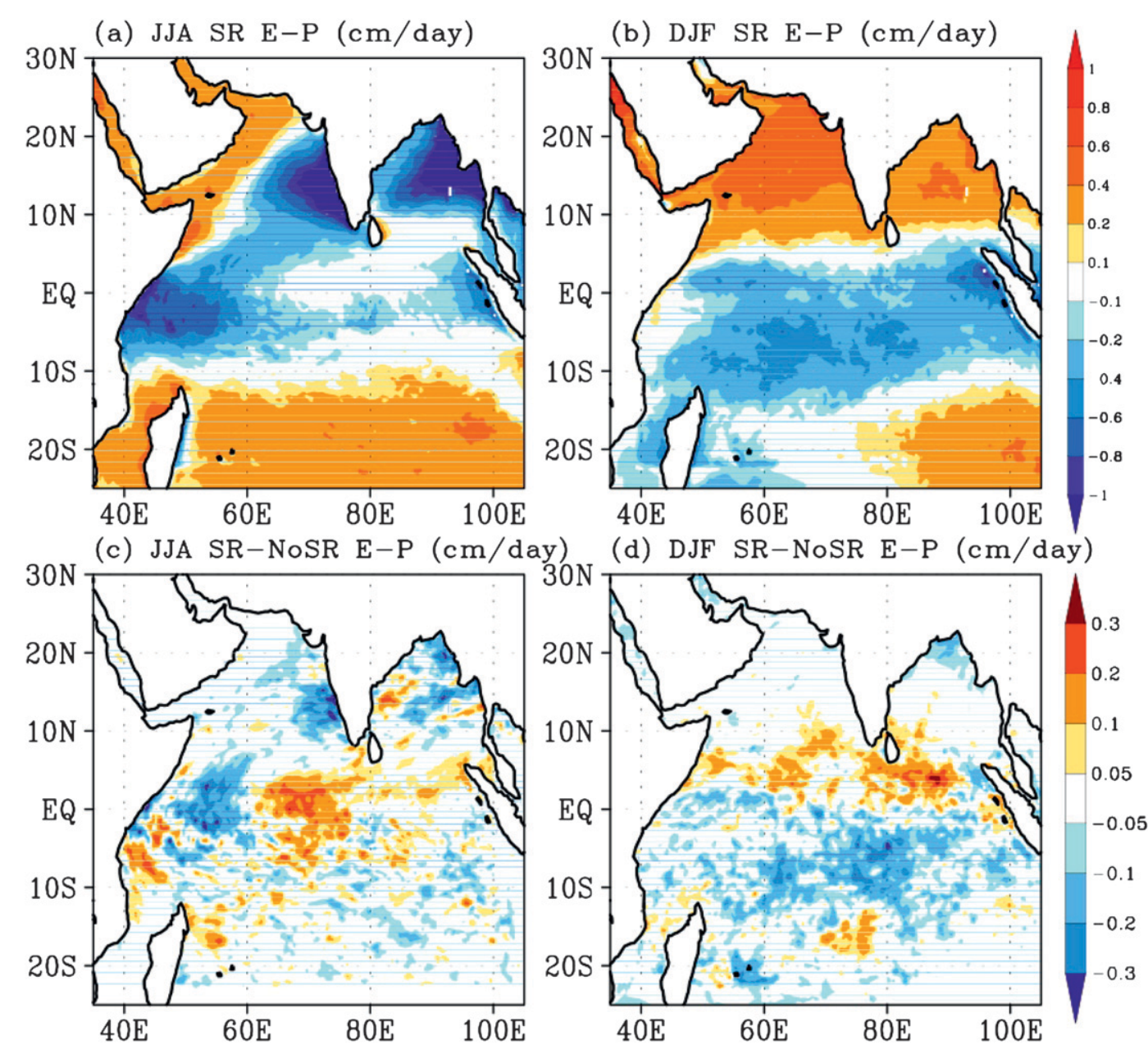

FIG. 1. Evaporation minus precipitation $\left(E-P, \mathrm{~cm} \mathrm{day}^{-1}\right)$ simulated from (top) SR and (bottom) the difference SR - NoSR averaged in (left) JJA and (right) DJF for 1993-2004.

coupler by the method discussed in detail by Seo et al. (2007).

For this study, we have set up the SCOAR model over the entire Indian Ocean from $30^{\circ} \mathrm{S}$ to $38^{\circ} \mathrm{N}, 29^{\circ}$ to $112^{\circ} \mathrm{E}-$ extending from eastern Africa to the eastern Indian Ocean (see Fig. 1 for the model domain). The horizontal resolution for the ocean and atmospheric component of the coupled model is identical at $0.26^{\circ}$. The ocean (atmospheric) model uses 20 (28) sigma layers in the vertical. There are roughly 12 layers in the upper $100 \mathrm{~m}$ in the BoB. The vertical mixing in the model is parameterized using a K-profile parameterization scheme (Large et al. 1994) including penetrative shortwave heating effects (Paulson and Simpson 1977) with a background vertical viscosity (diffusivity) of $5 \times 10^{-5}$ $\left(5 \times 10^{-6}\right) \mathrm{m}^{2} \mathrm{~s}^{-1}$.

To obtain the oceanic initial condition for the coupled model, the ROMS was first spun up for eight years, forced with monthly climatological atmospheric forcings inter- polated from the Comprehensive Ocean-Atmosphere Data Set (da Silva et al. 1994) and the monthly climatological oceanic boundary conditions derived from the World Ocean Atlas 2005 (WOA05) (Locarnini et al. 2006; Antonov et al. 2006). The end state from this spunup forced ocean run is used as initial condition for ROMS in the coupled mode. The RSM in the coupled run is initialized on 1 January 1993 using the National Centers for Environmental Prediction (NCEP)/Department of Energy (DOE) Reanalysis 2 (RA2) (Kanamitsu et al. 2002), which is also used to constrain the low-wavenumber atmospheric flows over the domain. The coupled run is then performed for 12 years from 1993 to 2004 with a daily exchange of surface fluxes (total heat flux, net freshwater flux, downward shortwave radiation, and momentum fluxes) and SSTs. The model monthly climatology is constructed based on the 12-year model outputs, and we will mainly display the difference fields of the monthly climatology of the two experiments, emphasizing the 
seasonal response during summer [June-August (JJA)] and winter [December-February (DJF)].

The RSM employs a scale-selective spectral nudging technique, as documented in Kanamaru and Kanamitsu (2007) and updated by Yoshimura and Kanamitsu (2008). This technique is designed to minimize systematic large-scale errors in the downscaling procedure while retaining the regional-scale processes such as river plumes from the mouth of rivers in the BoB. As will be shown in section 4, however, despite this spectral nudging technique, the simulated large-scale mean features deviate from the base fields (i.e., RA2), resulting in noticeable mean bias errors in the model.

\section{b. Observational data}

To verify the model simulation (1993-2004) against the observations, the following observational products are obtained and interpolated to the model's horizontal and vertical grids. The ocean temperature and salinity $(T / S)$ from the WOA05 are used to compare the surface and subsurface climatology. We also estimate BLT, MLD, ILD, and the depth of the $20^{\circ} \mathrm{C}$ isotherm $\left(Z_{20}\right)$, as a proxy for the thermocline depth, from the $T / S$ climatology of WOA05. Monthly SST data are obtained from the NOAA optimum interpolation (OI) SST analysis on a $1^{\circ}$ grid (Reynolds et al. 2002). Three precipitation products are used in this study: 1) the monthly Global Precipitation Climatology Project (GPCP) version 2 (Adler et al. 2003) on a $2.5^{\circ}$ grid, 2 ) the Climate Prediction Center Merged Analysis of Precipitation (CMAP) on a global $2.5^{\circ}$ grid (Xie and Arkin 1997), and finally 3 ) the monthly Tropical Rainfall Measuring Mission (TRMM) precipitation product 3B43 Version 6 (Huffman et al. 2007) that combines the TRMM data with an estimate from the global gridded rain gauge data on a $0.25^{\circ}$ grid. The TRMM data are only used for comparison during the shorter period of 1998-2004 but with a resolution closer to the model's one. Finally the 10-m wind fields are obtained from the monthly averaged NCEP reanalysis 2 on a global T62 Gaussian grid.

\section{Design of experiments and validation of salinity fields}

To capture the effects of freshwater forcing introduced by river discharge and to connect the evaporation minus precipitation $(E-P)$ errors in the open ocean, two coupled simulations are performed. In the first experiment, termed salinity restoring (SR), SSS is relaxed to the WOA05 monthly climatological SSS over the entire domain. Thus, in SR, surface salinity is relaxed to the sum of climatological evaporation, precipitation, and river runoff. In a complementary coupled experi- ment, no SSS restoring (NoSR) is applied in the ocean. SSS in the NoSR run hence is determined by the simulated $E-P$ only, without the freshwater forcing from the river discharges.

A restoring of surface salinity implies that the resultant SSS difference is not only due to the river discharge but also the simulated $E-P$ in NoSR, which is different from the climatological $E-P$ used in SR. Figure 1 illustrates the difference in $E-P$, comparing two experiments for boreal summer and winter. Generally, the spatial patterns of $E-P$ (Figs. 1a,b) are dominated by the seasonal mean precipitation patterns associated with the Indian monsoon in both runs (Prasad 1977; Harenduprakash and Mitra 1988). The magnitude of $E-P$ during JJA exceeds $1 \mathrm{~cm}$ day $^{-1}$ in the Arabian Sea, BoB, and western Indian Ocean. In JJA, the spatial pattern of the $E-P$ difference at the equator (Fig. 1c) resembles that of SSS (Fig. 2e). With little impact on salinity by river discharge in the open ocean, this suggests that the difference in $E-P$ is responsible for the SSS difference. In BoB and SEAS, on the other hand, the $E-P$ and SSS do not show the agreement (Fig. 2e) but, instead, the $E-P$ pattern is well matched with the rainfall pattern (Fig. 11c in section 5c), which implies that the latter causes the former.

In DJF (Fig. 1d), there is nearly no difference in $E-P$ in the BoB and SEAS between the two runs, while there is a large change in SSS (Fig. 2f) and no change in rainfall (Fig. 11d). This indicates that the freshwater flux from river discharge plays a dominant role in determining change in surface salinity there. It is shown later that the spatial pattern of $E-P$ in the open ocean during DJF (Fig. 1d) is a direct consequence of the precipitation response to this large SSS change in the BoB and SEAS (section 5).

Figures 2 and 3 illustrate the resultant salinity field in the model in comparison to observations. In the observations (Figs. 2a,b), low salinity waters fill the entire bay throughout the year, with the freshest water mass having less than 28 psu along the coast adjacent to the major river mouths. This results in a very large lateral haline gradient. From a time series of hydrographic observations conducted in the northern $\mathrm{BoB}$ during the summer of 1984 on board ORV Sagar Kanya, Murty et al. (1992) reported the large SSS gradient from the open bay (35 psu) toward the northern BoB (16 psu). The WOA05 well captures this spatial distribution with, for example, low salinity from the river runoff (e.g., 20.5 psu in December at $21^{\circ} \mathrm{N}, 88^{\circ} \mathrm{E}$ ) that increases sharply toward the center of the bay $\left(32.8\right.$ psu at $15^{\circ} \mathrm{N}, 88^{\circ} \mathrm{E}$ in December). Figures 2c,d show the differences of simulated SSS from SR and the WOA05, while Figs. 2e,f show the difference between SR and the NoSR. Figure 2 indicates that NoSR 
(a) JJA WOA05 SSS

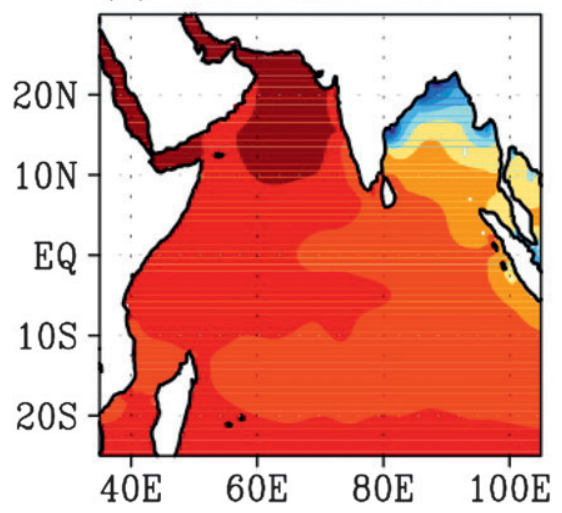

(c) JJA SR - WOA05

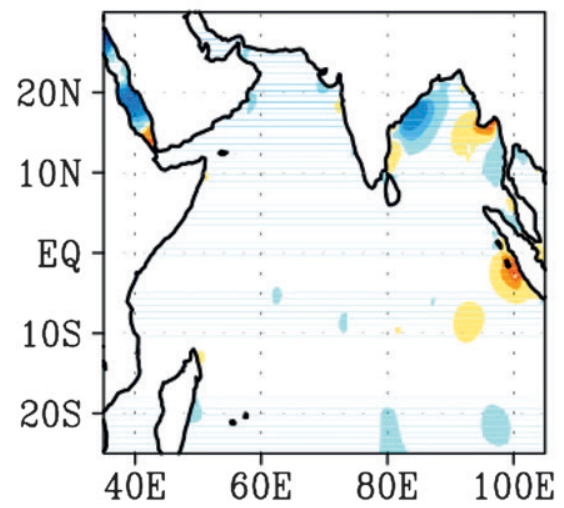

(e) JJA SR - NoSR

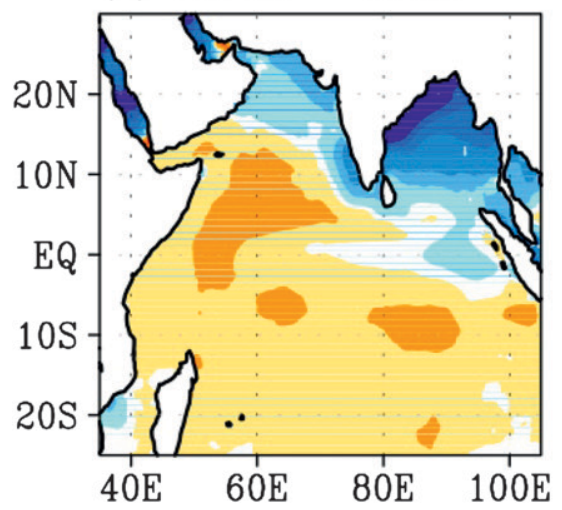

(b) DJF WOA05 SSS
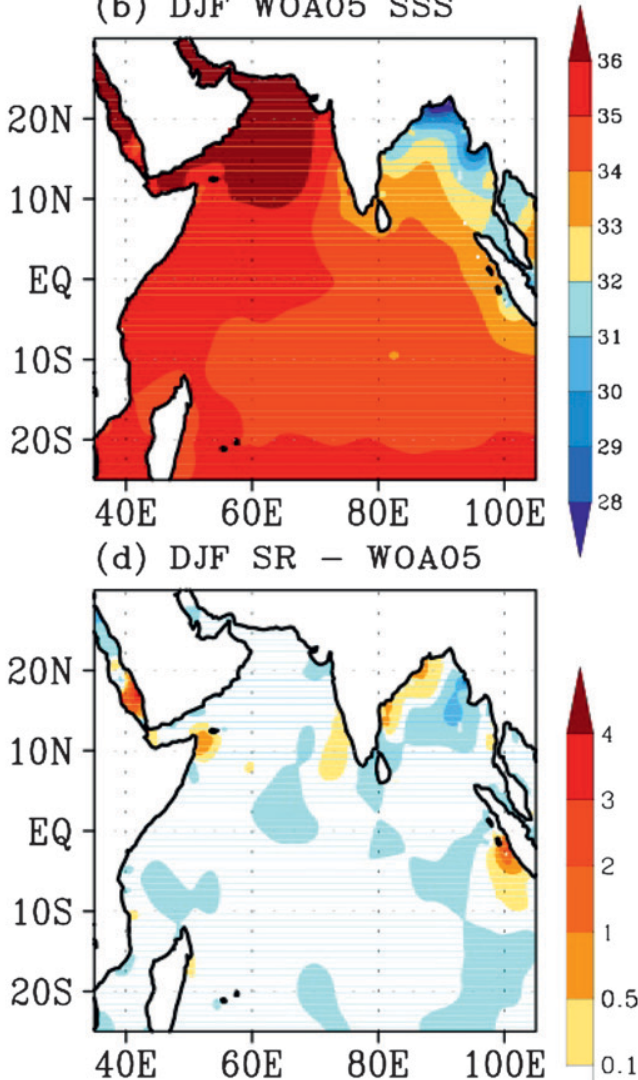

(f) DJF SR - NoSR

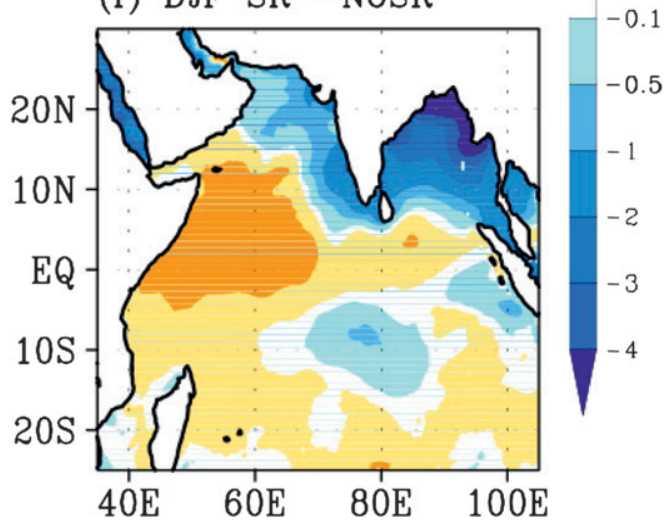

FIG. 2. Sea surface salinity (psu) averaged for (left) JJA and (right) DJF 1993-2004: (top) WOA05, (middle) difference in SSS between NoSR and WOA05, and (bottom) SSS difference between SR and NoSR. The original domain covers $30^{\circ} \mathrm{S}-38^{\circ} \mathrm{N}, 29^{\circ}-112^{\circ} \mathrm{E}$, but here the domain is shown excluding the lateral boundary sponge layer in the east and south and the land points in the west and north.

run produces too high salinities both in the bay and in the northern Indian Ocean in summer and winter, which is due to the absence of river discharge. In the Arabian Sea and the rest of the domain, NoSR produces generally lower salinity than observed. This seems to be related to the model errors in wind and rainfall (section 4).

When the SSS relaxation is imposed in the SR run, these errors in SSS are substantially reduced throughout the domain. The strong lateral salinity gradient is much better captured in the SR run in both seasons, and the difference in SR and NoSR clearly demonstrates the improvement in the salinity fields in the SR relative to NoSR. However, there are patches of lower ( -2 psu) and higher $(+0.5 \mathrm{psu})$ SSS. These patches are seen as errors arising from the restoring of salinity in regions with large salinity gradients to the smoothed salinity products such 

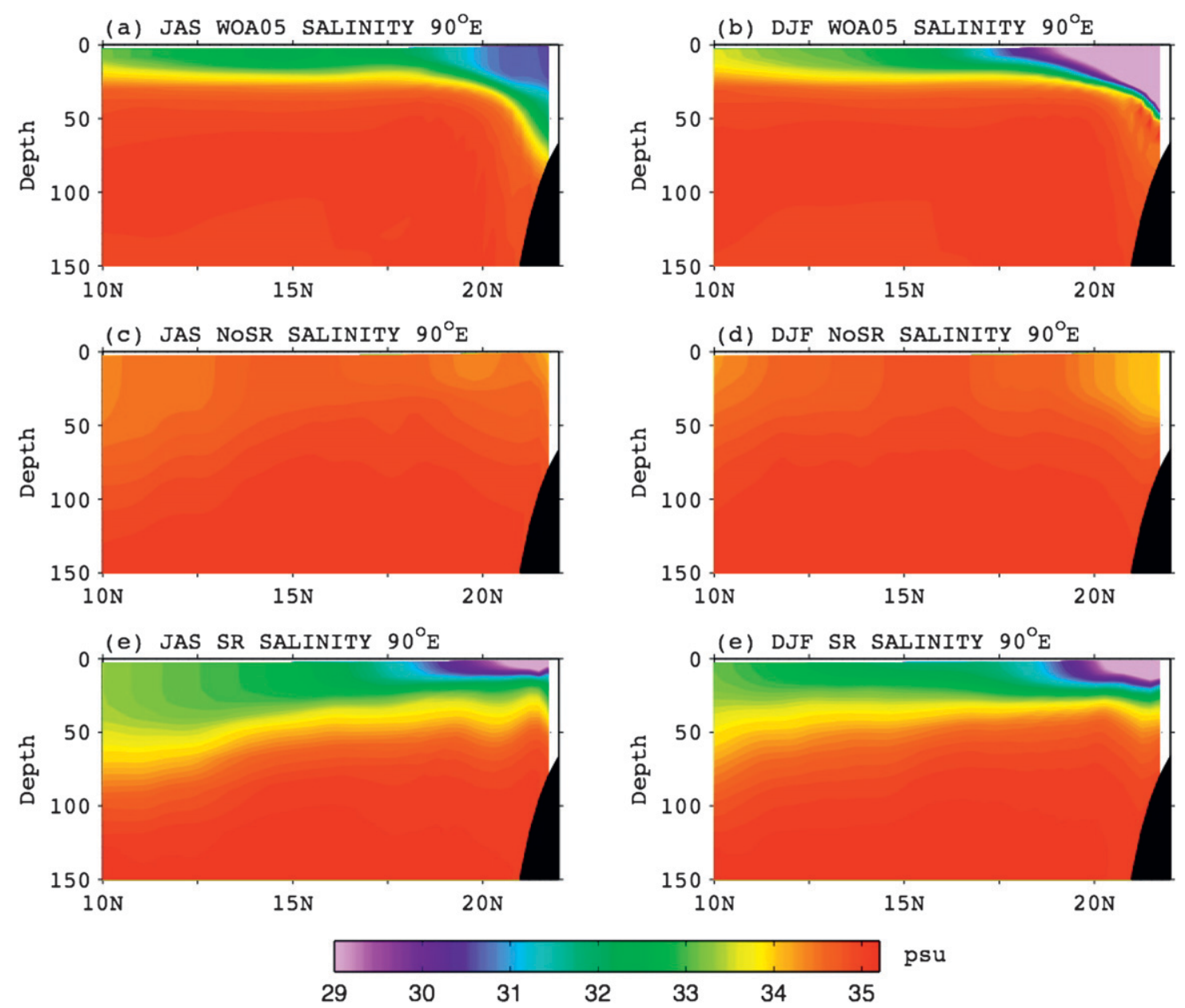

FIG. 3. Depth-latitude diagrams of salinity along $90^{\circ} \mathrm{E}$ for (top) $W O A 05$, (middle) NoSR, and (bottom) SR averaged for (left) JJA and (right) DJF from 1993 to 2004.

as WOA05 (Yu and McCreary 2004). In such regions, SSS restoring is particularly sensitive to the chosen relaxation time scale. We have chosen a strong relaxation $(\tau=$ 10 days), which, as is revealed in Fig. 2, reproduces the spatial patterns of the observed salinity quite well but can sometimes overshoot the SSS differences and switch its sign in the regions of large salinity gradient.

The subsurface salinity distribution in the $\mathrm{BoB}$ also improves in SR. Figure 3 shows the transects of salinity along $90^{\circ} \mathrm{E}$ in the BoB. The simulated salinity field in SR exhibits a strong halocline at the observed depth during both seasons, which is missing in the NoSR case. Although the SR run underestimates the isohaline sloping down toward the coast as reported in the observations (Shetye et al. 1996) and also produces the too-deep and thick halocline in the south of Bay, the simulated horizontal and vertical salinity structure produces far more realistic salinity distribution in SR than in the NoSR case in both seasons.
HM01 included the river discharges locally as surface freshwater flux at the mouths of rivers in their ocean model. This methodology is deemed more appropriate to incorporate river discharges in the numerical model than our approach. Their simulated SSS pattern nevertheless does not completely remove the SSS errors and is somewhat similar to what is shown in Figs. 2e,f, lending some justification to the use of a simple SSS relaxation. Note that a study by Kurian and Vinayachandran (2007) well reproduced the climatological SSS patterns by prescribing the river discharge in their high-resolution OCGM. Their success appears to be due to the relatively higher horizontal and vertical resolution used in their model along with the realistic surface forcings. While our horizontal resolution is comparable to what is used in their study, the number of vertical layers used in our ocean model is only half of theirs, which is closer to the 19 vertical layers used by HM01. Since the BL effects on SST and the definitions of the oceanic variables such as 
MLD and BL critically depend on vertical processes and the resolutions of the model (Kara et al. 2000), we expect the results to be more similar to those from HM01, if the river discharge were imposed locally.

In summary, despite the limitation of the experimental setup, the comparison of $E-P$ fluxes and SSS indicate that the SSS relaxation method captures important aspects of Indian Ocean salinity variations reasonably well (e.g., seasonal cycle) and, hence, is capable of offering useful insights on the role of freshwater oceanic forcing affecting the large-scale atmospheric circulation.

\section{Validation of model climatology}

Before we investigate the sensitivity of the system to surface freshening, this section discusses the seasonal mean biases displayed by the current model. Figure 4 shows plots of SST, $10-\mathrm{m}$ wind and precipitation from the observations (OBS), SR run, and the difference or error (SR - OBS).

The model summer climatology in rainfall, wind, and SST broadly resembles the observed patterns, with the Somali jet directed from southwest to northeast along the coast of Somalia, resulting in coastal filaments and the Great Whirl (Schott and McCreary 2001). The southwesterly monsoon wind impinges on India and Indochina, with windward rainfall maxima. From satellite observations, Xie et al. (2006) discussed the orographic lift acting on the SW monsoon wind over coastal mountains. The model appears to mimic the observed pattern but overestimates the magnitudes of orographic rainfall. Excessive rainfall is found over Indochina and the western Arabian Sea (see Table 1), and further investigation is required to understand the origin of these errors in simulated rainfall.

Summertime warm bias errors are found in SST over the western Indian Ocean, the Arabian Sea, and broad regions of the south Indian Ocean. As discussed in Seo et al. (2008), the summertime warm bias in the Arabian Sea is due to the underestimation of the Somali jet in the model, which appears to be linked to model errors in the large-scale atmospheric wind (Seo et al. 2008, their Fig. 2). This results in weak coastal upwelling and higher SST in the Arabian Sea and at Omani coast, which produce excessive rainfall during the SW monsoon. This pattern of summertime mean errors is common, to a varying degree, among the existing CGCMs (Annamalai et al. 2007; Bollasina and Nigam 2008).

The warm bias persists in the Arabian Sea throughout the year and is associated with the model's tendency to produce too deep thermocline depths year-round (Fig. 5). More importantly, in the southwestern Indian
Ocean, the model only vaguely captures the salient feature of the observed oceanic thermocline dome. The amplitude and location of this thermocline dome is reasonably well simulated in many CGCMs, while some models still produce patterns similar to those seen in Fig. 5b (Saji et al. 2006). Vecchi and Harrison (2004) and Izumo et al. (2008) noted that anomalously warm SST over the thermocline dome and in the western Arabian Sea can result in excessive precipitation in the Western Ghats, indicating the importance of capturing the thermocline structure for precipitation simulation during the SW monsoon. The current model places its shallow thermocline too far west at $5^{\circ} \mathrm{S}, 45^{\circ} \mathrm{E}$ where it is forced by the local cyclonic wind forcing. In the western Indian Ocean, the excessively deep thermocline roughly coincides with the region of warm SST bias at $5^{\circ} \mathrm{S}, 50^{\circ} \mathrm{W}$ (Fig. 4i) and the corresponding excessive precipitation (Fig. 4k). Thus the errors in mean SST and precipitation are dynamically consistent with those of subsurface thermocline structure.

Furthermore, the basin-scale pattern of the warm bias in the west and the cold bias in the eastern equatorial ocean and the BoB resembles that associated with the Indian Ocean zonal dipole mode (IOZDM; Webster et al. 1999; Saji et al. 1999), which generates the Indian summer monsoon rainfall anomalies that are qualitatively similar to Fig. 4k (Behera et al. 1999; Annamalai et al. 2003). This indicates that a portion of the summertime model bias is linked to the mean state errors that bear some resemblance to the spatial patterns of the IOZDM. All this suggests that the mean bias errors described so far can be viewed as a result of the model's errors in simulating realistic large-scale winds and the amplification by air-sea interaction. The overall amplitude of mean bias errors is more pronounced during the boreal summer.

Over the BoB, SST displays cold biases, especially during the summer, possibly due to errors in surface wind and thermocline depth. Despite the cold bias, the model simulates too strong precipitation during summer over the $\mathrm{BoB}$ except on the east coast of India where spurious upwelling occurs. Thermohaline forcing is strong in the $\mathrm{BoB}$, and sections 5 and 6 investigate the effect of salinity stratification on SST and the atmosphere.

Table 1 compares the simulated precipitation in two key regions of the largest bias with the observations for JJA and DJF: one along the Western Ghats and the other over the BoB and Indochina. Seasonally, the summer rainfall bias increases slightly in the SR run compared to NoSR, while the winter rainfall bias displays a moderate improvement. The difference in rainfall between SR and NoSR is smaller compared to their mean values in summer $(\sim 3 \%-6 \%)$ than in winter $(\sim 11 \%)$. 

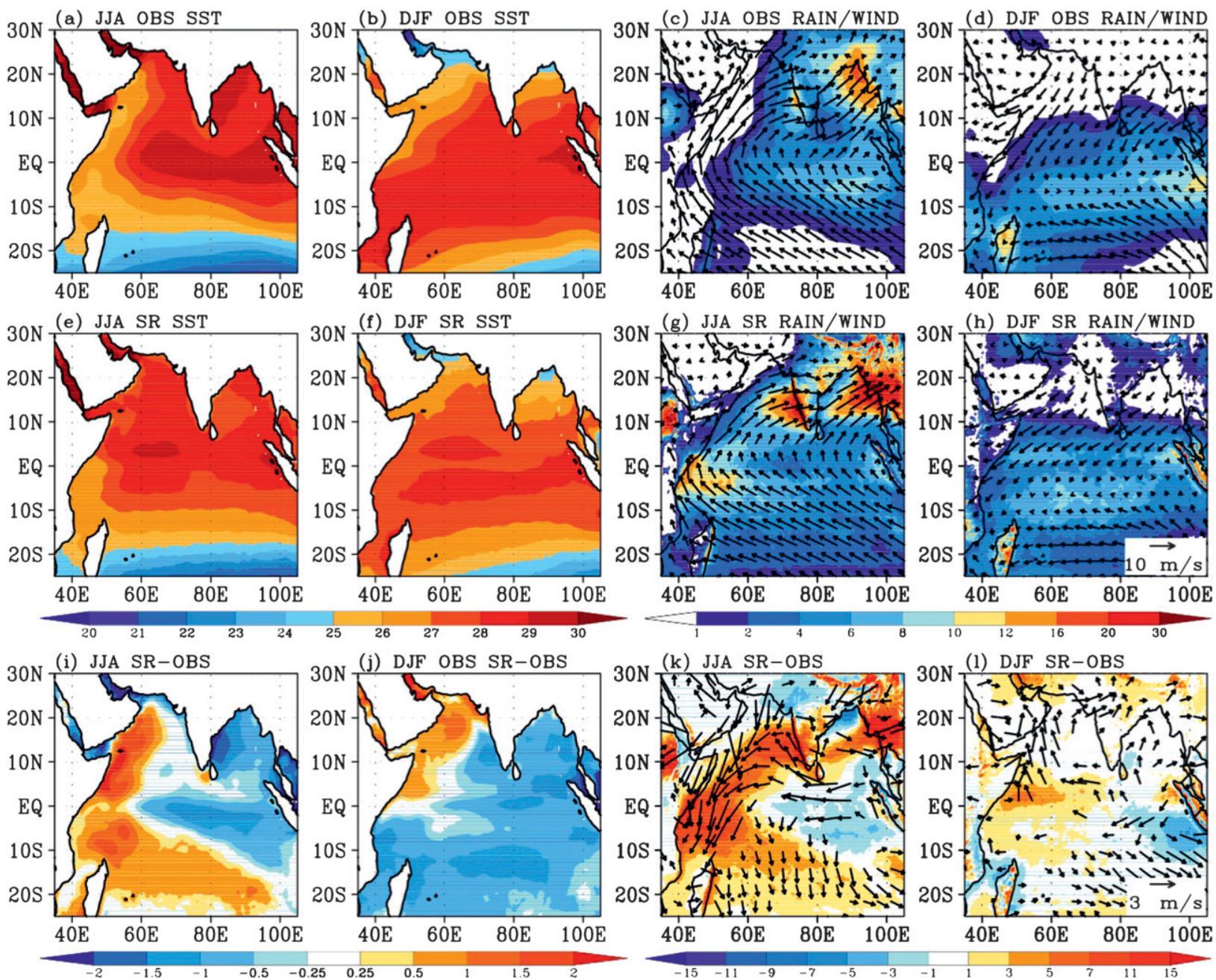

FIG. 4. Twelve-year (1993-2004) mean (top) obsevations (OBS), (middle) model (SR run), and (bottom) SR - OBS. Left (right) two panels show SST $\left({ }^{\circ} \mathrm{C}\right)$ [precipitation $\left(\mathrm{mm} \mathrm{day}^{-1}\right)$ and $10-\mathrm{m}$ wind $\left(\mathrm{m} \mathrm{s}^{-1}\right)$ ] with JJA (DJF) averages for first and third (second and fourth) columns. Observations are from the NOAA OI SST, the GPCP precipitation, and the NCEP/DOE RA2 10-m winds, all of which are averaged for the same time period as in the model. (h),(l) Reference vectors are shown. (k),(l) Wind vectors with wind speed less than $3 \mathrm{~m} \mathrm{~s}^{-1}$ are not omitted for clarity.

Weaker sensitivity of the model precipitation to the freshwater forcing in summer implies that other factors such as wind anomalies (Shukla 1987; Murtugudde and Busalacchi 1999; Murtugudde et al. 2007) and their feedback to the SST (Wang et al. 2005) can be more important for the Indian summer monsoon. In wintertime, the model error is smaller and the model exhibits greater sensitivity to the salinity. For the rest of the paper, we will discuss sensitivity of the coupled system in the Indian Ocean to freshwater forcings for both seasons, but the wintertime response will be emphasized for this reason.

The large rainfall biases are common in state-of-theart climate models (Annamalai et al. 2007). Because of

TABLE 1. Precipitation $\left(\mathrm{mm} \mathrm{day}^{-1}\right)$ in the Western Ghats $\left(5^{\circ}-20^{\circ} \mathrm{N}, 60^{\circ}-80^{\circ} \mathrm{E}\right)$ and $\mathrm{BoB}$ and Indochina $\left(13^{\circ}-23^{\circ} \mathrm{N}, 80^{\circ}-105^{\circ} \mathrm{E}\right)$.

\begin{tabular}{llrrrrrr}
\hline \hline & & SR & NoSR & GPCP & CMAP & TRMM & (SR - NoSR)/NoSR \\
\hline Western Ghats & JJA & 9.0 & 8.7 & 6.1 & 5.1 & 5.1 & $3.4 \%$ \\
\multirow{2}{*}{ BoB + Indochina } & DJF & 1.5 & 1.7 & 0.7 & 0.9 & 0.7 & $11.7 \%$ \\
& JJA & 17.0 & 16.0 & 10.3 & 11.0 & 10.0 & $6.2 \%$ \\
& DJF & 0.8 & 0.9 & 0.6 & 0.5 & 0.4 & $11.1 \%$ \\
\hline
\end{tabular}


(a) ANN WOA05 Z20
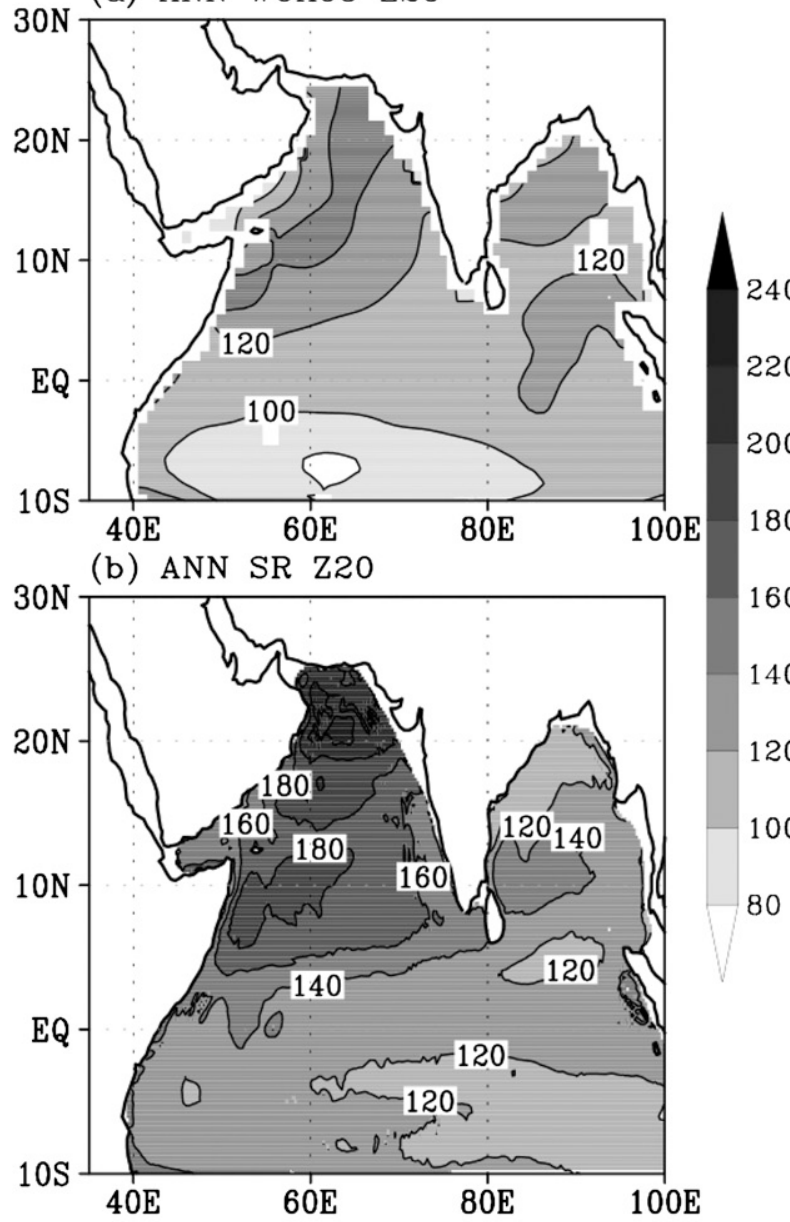

(c) ANN SR-NoSR Z20

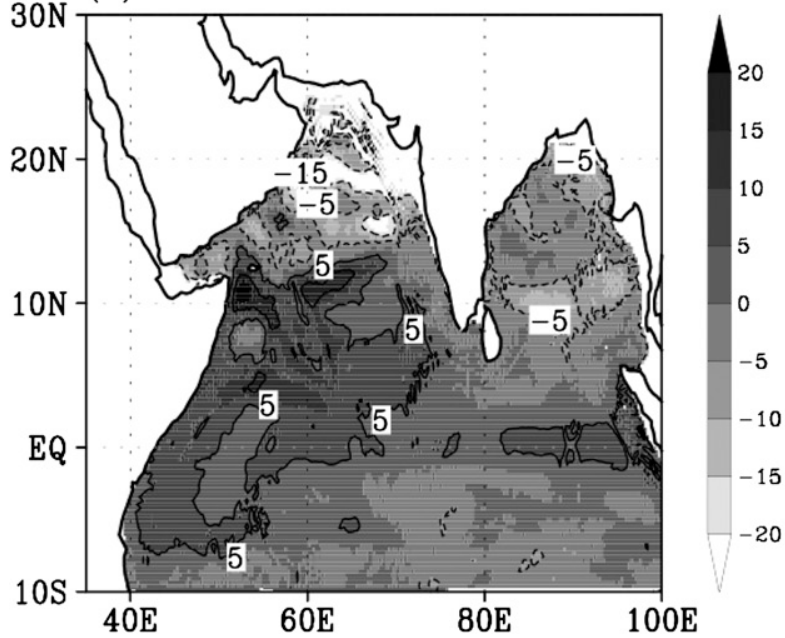

FIG. 5. Annual mean (1993-2004) thermocline depths from (a) WOA05, (b) SR, and (c) SR - NoSR. Thermocline depths are derived from the depth of the $20^{\circ} \mathrm{C}$ isotherms. the complicated interaction of ocean, atmosphere, and land, such mean state errors limit the ability of models as tools to study climate dynamics. Despite such biases present in the current model, the large salinity difference of 3-4 psu over the BoB (Fig. 2) suggests that our results about its climate effects are likely to hold. Further study is necessary as coupled models improve in the future.

\section{Oceanic changes}

\section{a. Oceanic vertical structures}

The influence of lower salinity on the oceanic vertical structure can be seen in Figs. 6 and 7. The top (bottom) panel of Fig. 6 shows the mean seasonal cycle of salinity and temperature as a function of depth in the BoB from SR (SR - NoSR). Figure 7 shows the mean profiles of temperature $(T)$, salinity $(S)$, and the density $\left(\sigma_{\theta}\right)$ averaged over the same region for summer and winter. The largest variation in salinity between SR and NoSR is found in the upper $80 \mathrm{~m}$ of the ocean with the greatest reduction of salinity in SR exceeding 4 psu at the surface from June to February (Fig. 6c). Accordingly, a strong halocline develops in salinity profiles in SR at $\sim 40 \mathrm{~m}$ (Figs. 7a,d), while the salinity profile is more or less uniform in NoSR (Figs. 7b,e). The enhanced upperocean salinity gradient leads to density stratification in $\mathrm{SR}$, indicating that salinity plays a dominant role in determining upper-ocean stratification and the MLD.

Figure 7 a shows that summertime vertical temperature distribution in SR is much more uniform within the mixed layer compared to the winter monsoon period when the upper-ocean temperature displays a strong subsurface inversion at $30 \mathrm{~m}$ (Fig. 7d). This indicates that the salinity signal remains strong in winter and modulates the upper-ocean mixing through the density stratification and temperature inversion. A careful inspection of the summertime temperature profile (Fig. 7a) reveals a weak temperature inversion (see also Fig. 7c). During the Bay of Bengal Monsoon Experiment (BOBMEX), Vinayachandran et al. (2002) observed such an inversion layer in the northern bay in August with maximum amplitude $0.5^{\circ} \mathrm{C}$ at $30-\mathrm{m}$ depth. This was attributed to the net surface cooling during cloudy days (Bhat et al. 2001) and some contribution from the Ekman transport of low saline water to the observation site. During JJA in the model, the net heat flux is slightly positive (warming the ocean) in both runs but total heat flux in SR is smaller than in NoSR (Fig. 8a). The reduction in net heat flux in SR is partly attributable to the decreased downward shortwave radiation, in support of the observational study of Vinayachandran et al. (2002). 
(a) SR BOB SALINITY

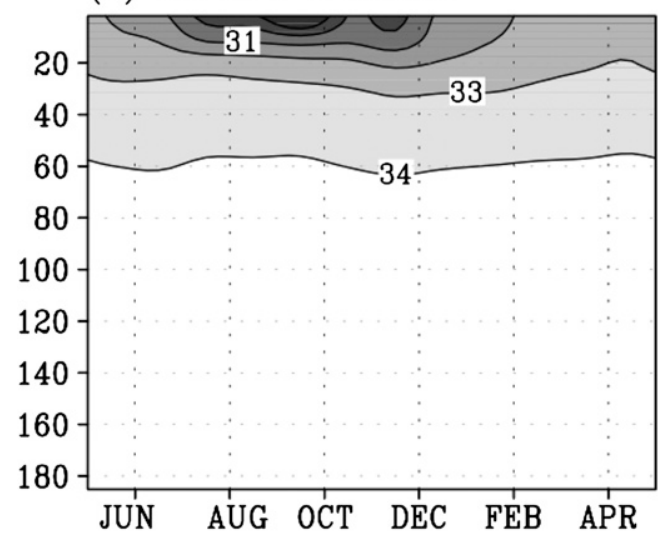

(c) SALINITY: SR-NoSR

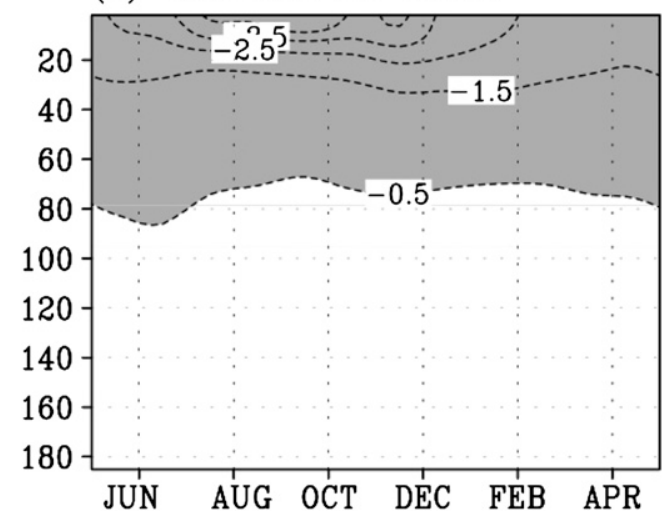

(b) SR BOB TEMPERATURE

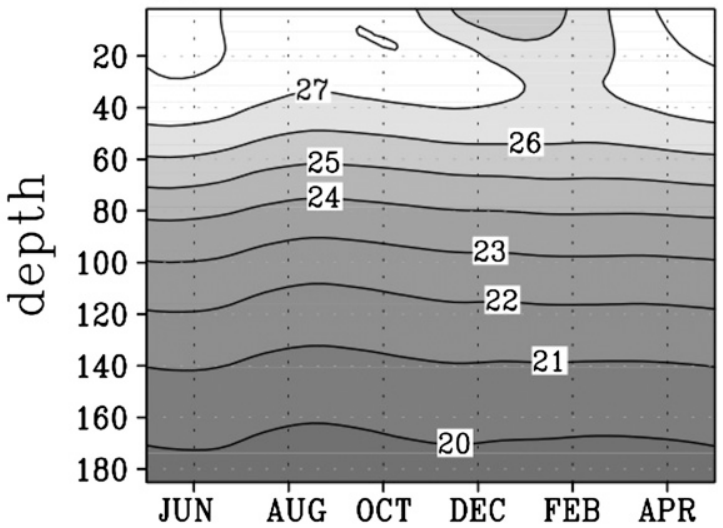

(d) TEMPERATURE: SR-NOSR

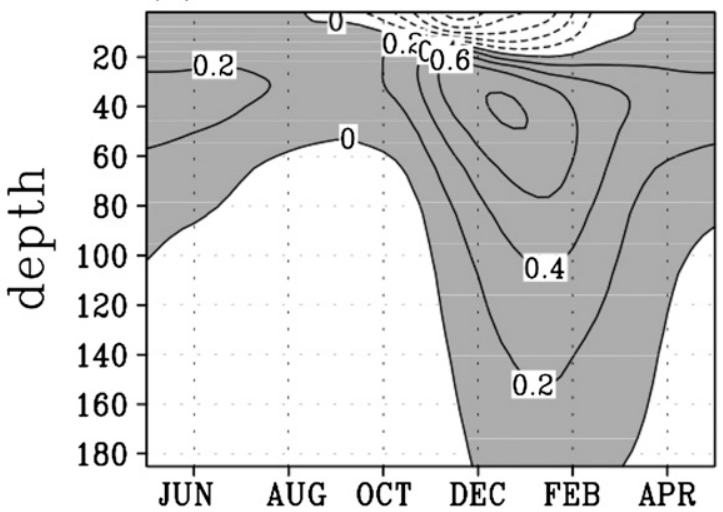

FIG. 6. Time-depth diagrams of mean seasonal cycle of (a) SR salinity (psu) over the Bay of Bengal $\left(10^{\circ}-25^{\circ} \mathrm{N}\right.$, $\left.80^{\circ}-100^{\circ} \mathrm{E}\right)$, (b) SR temperature $\left({ }^{\circ} \mathrm{C}\right)$ as in (a),(c) salinity difference (SR - NoSR), and (d) temperature difference (SR - NoSR). The contour intervals in (a) and (c) are 1 and $0.5 \mathrm{psu}$, respectively; values less than -0.5 psu shaded in (c). The contour intervals for (b) and (d) are $1^{\circ}$ and $0.2^{\circ} \mathrm{C}$, respectively; positive values shaded in (d).

Figure 9 shows the seasonal cycle of the $\mathrm{BL}$ averaged over the $\mathrm{BoB}$, derived from the WOA05 and from the models. Also shown is the most recent estimate of the global BLT by DMLC07 derived from the National Oceanographic Data Center (NODC), World Ocean Circulation Experiment, and Argo databases of measured temperature and salinity profiles. Figure 10 shows the spatial maps of the BLT from the WOA05 and the model simulation for the two seasons. In WOA05, BLs start to develop at the beginning of the summer monsoon season with the maximum thickness occurring during the boreal winter. DMLC07 and Mignot et al. (2007) showed that the $\mathrm{BoB} \mathrm{BL}$ is a quasi-permanent feature, persisting for 10 months per year and reaching its maximum thickness in the boreal winter. The seasonal cycle of the BL from the WOA05 is qualitatively consistent with their findings, yet the accurate timing of the maximum of the BLT is in January in DMLC07, while it is in February in WOA05.

The $\mathrm{BL}$ is generally thinner throughout the year, especially during boreal summer, with a markedly larger sea- sonal cycle in DMLC07 than in the smoothed WOA05 dataset. Note that the estimate of BLs from DMLC07 is based on the $\Delta T=0.2^{\circ} \mathrm{C}$ criterion that is applied to the individual profiles (with higher vertical resolutions) before being spatially mapped, while the BLs from WOA05 and from the model are based on spatially and temporally averaged data (Kara et al. 2003). So a difference in seasonal cycle and accuracy exists between the two estimates. In this study we use the estimate from the WOA05 because the rather coarse vertical resolution in the model (20 vertical layers) favors comparison with the already smoothed fields in WOA05. Furthermore, the monthly WOA05 climatology is used for the lateral boundary conditions of the ocean model and the SSS is restored to the WOA05 fields.

Note that, despite the strong resorting of salinity, SR does not capture the rapid (monthly) extremes in August and February as in WOA05 (Fig. 9). The seasonal cycle of BLT in SR is, in fact, similar to that of NoSR except for difference in annual mean values. Hence the 
(a) JJA SR

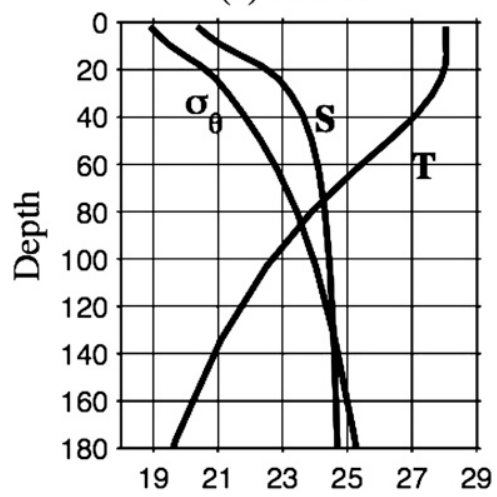

(d) DJF SR

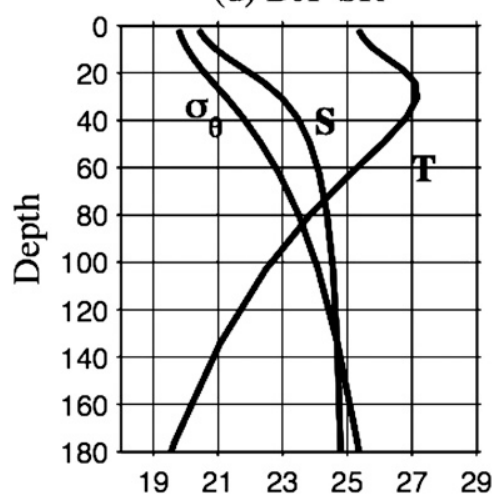

(b) JJA NoSR

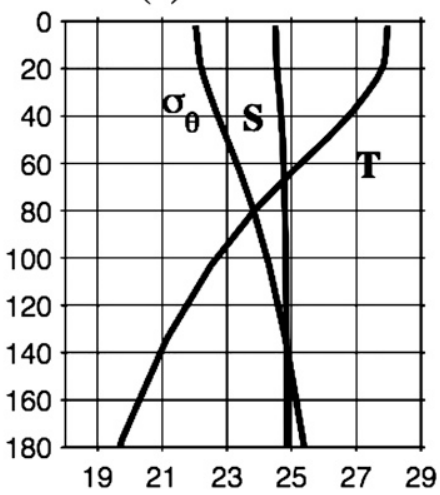

(e) DJF NoSR

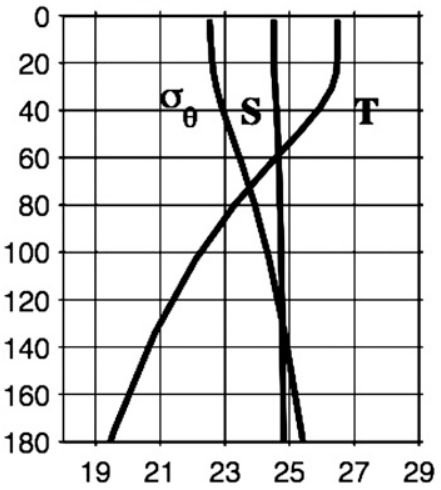

(c) JJA SR-NoSR

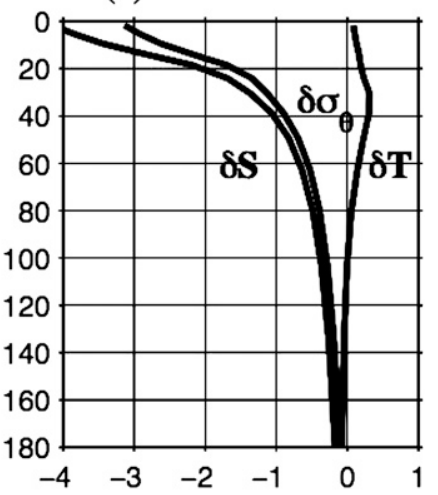

(f) DJF SR-NoSR

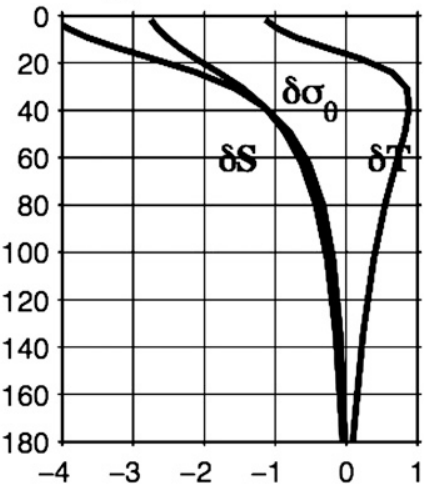

FIG. 7. (top) JJA and (bottom) DJF mean profiles of salinity $(S-10 \mathrm{psu})$, temperature $\left(T,{ }^{\circ} \mathrm{C}\right)$, and density $\left(\sigma_{\theta}\right)$ averaged over Bay of Bengal $\left(10^{\circ}-25^{\circ} \mathrm{N}, 80^{\circ}-100^{\circ} \mathrm{E}\right)$ from (a) SR, (b) NoSR, and (c) SR - NoSR. The quantities are averaged for 12 years (1993-2004). There are approximately 14 vertical layers in the upper $200 \mathrm{~m}(1.9,5.7,9.7,14.0$, 18.9, 24.7, 31.6, 40.1, 50.9, 64.9, 83.3, 107.7, 140.6, and $185.1 \mathrm{~m})$.

effect of restoring surface salinity appears to have the largest impact on the year-mean values of BLT, while its seasonal cycle is dominated by model climatology.

In JJA, WOA05 shows a 40-50-m thick BL along the coast of the bay, with maximum thickness of 50$60 \mathrm{~m}$ along the eastern coast (Fig. 10a). In DJF, the BLT reaches $70 \mathrm{~m}$ in the northern bay and the SEAS (Fig. 10b). The SR run qualitatively captures key aspects of these spatial patterns. Specifically, the 20-40-m thickness of the BL in the BoB and Arabian Sea in JJA and the thick BL centered in the BoB and SEAS in DJF are evident. However, the BLT in SR is generally underestimated throughout the domain compared to the WOA05 and some features of the BL in the eastern equatorial ocean are not reproduced. In particular, the BLT in the SEAS during DJF is thicker and spatially more extensive toward the Arabian Sea in SR than in WOA05. Note, however, that the NoSR run essentially fails to reproduce the important features of the BL in the Indian Ocean, including the spatial distribution and its seasonal cycle.

\section{b. Impact on summer SST}

Modulation of vertical stratification by salinity and the BL has an important effect on the ML temperature and SST. Figure 11a illustrates the spatial patterns of these changes in SST during JJA season. A local increase in SST can be found along the northwestern coast of the bay adjacent to the mouths of the major rivers, which warm up to $0.4^{\circ} \mathrm{C}$ with the inclusion of river runoff. However, the areal extents of this increase in SST are limited to the coastal boundaries and hence, when averaged over the entire Bay, the increase in SST is rather small, $0.1^{\circ} \mathrm{C}$ in this model. This is clearly not sufficient to offset the cold bias shown in Fig. $4 \mathrm{i}$ and implies that the effect of river input on SST is weak during summer and the cold bias in the model is more closely related to wind anomalies, as discussed in section 4 .

Since the isothermal layer is deep and the net surface heat flux is weak over the summer $\mathrm{BoB}$, the warming effect due to the weakened mixing is not pronounced. Furthermore, the surface heat flux acts as a damping 

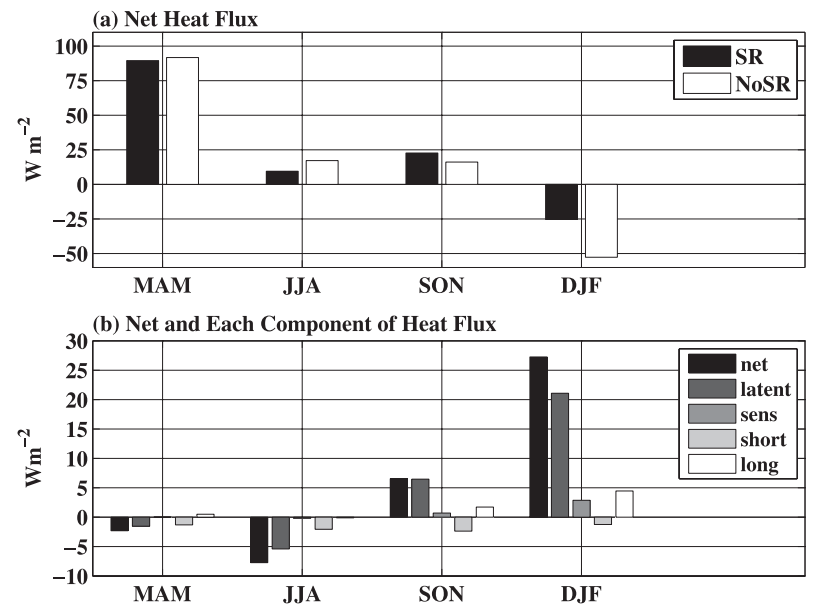

FIG. 8. (top) Surface net heat flux climatology $\left(\mathrm{W} \mathrm{m}^{-2}\right)$ from SR and NoSR as a function of season and (bottom) difference (SR - NoSR) of the net heat flux and each component of net heat flux, positive flux into the ocean, averaged over the $\mathrm{BoB}\left(10^{\circ}-25^{\circ} \mathrm{N}\right.$, $\left.80^{\circ}-100^{\circ} \mathrm{E}\right)$.

on this slight increase in SST. Figure 8a compares the seasonal mean net heat flux (positive warming ocean) between SR and NoSR, and Fig. $8 \mathrm{~b}$ shows the difference in net and each component of the net heat flux. The net heat flux in JJA in SR (NoSR) is $9 \mathrm{~W} \mathrm{~m}^{-2}\left(17 \mathrm{~W} \mathrm{~m}^{-2}\right)$, indicating that heat flux warming is reduced in SR over the warm water. This is largely explained by greater evaporative cooling and an increase in cloudiness that reduces the shortwave radiation reaching the surface (Vinayachandran et al. 2002).

In forced ocean model studies, Han and McCreary (2001) and Han et al. (2001) suggested a significant local increase in SST in the northwest corner of the bay during the summer monsoon with the inclusion of river discharges. However, our results suggest that the basinaverage increase in SST is small. HM01 also showed that BoB SST, indeed, would warm with the inclusion of river influx into the $\mathrm{BoB}$, but this increase is generally small and occurs only without the effect of the penetrative solar heat flux loss due to the thinning of the ML (Godfrey and Lindstrom 1989; Murtugudde et al. 2002). With the inclusion of the penetrative shortwave heating effect, which is parameterized in the ROMS model (Large et al. 1994), SST generally decreases in their experiment. From the analysis of the buoy data in the BoB, Sengupta and Ravichandran (2001) also showed that low salinity offsets the heat flux warming by allowing more sunlight to penetrate below the ML. Thus there is substantial modeling and observational evidences that low salinity due to the riverine input could increase the SST in BoB, but the overall change is small owing to the offset by surface flux adjustments.

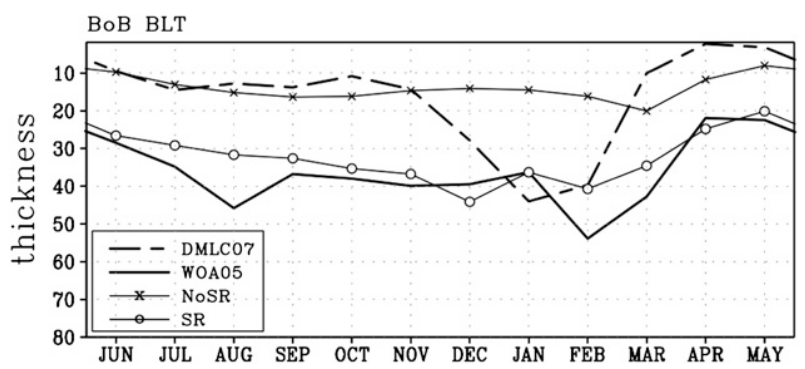

FIG. 9. Seasonal cycle of BLT in the BoB $\left(10^{\circ}-25^{\circ} \mathrm{N}, 80^{\circ}-100^{\circ} \mathrm{E}\right)$ estimated from the observations and the models. BLT is calculated by the positive difference between the depth at which temperature becomes less than the SST by $\Delta T=1^{\circ} \mathrm{C}$ and the depth at which salinity effects on density variations are equivalent to a $\Delta T=1{ }^{\circ} \mathrm{C}$ decrease of temperature.

Regarding the SST changes in summer, the equatorial Indian Ocean deserves some attention. A large increase in SST is found at $55^{\circ} \mathrm{E}$ and moderate cooling is located at $70^{\circ} \mathrm{E}$, both at the equator. These changes in SST are similar in spatial patterns to the difference in SSS (Fig. 2e), with the higher (lower) salinity at $50^{\circ} \mathrm{E}\left(\right.$ at $\left.70^{\circ} \mathrm{E}\right)$, indicating that the SSS restoring is partly responsible. These anomalies are also consistent with the changes in the thermocline depth (Fig. 5c), which deepens at $50^{\circ} \mathrm{E}$ where it warms but shoals at $70^{\circ} \mathrm{E}$ where it cools. The change in equatorial SST bears little direct influence from the river discharges, and instead is likely associated with the model mean errors in locating the thermocline dome and the basinwide SSS relaxation. The atmospheric response to the summertime SST pattern will be discussed in section 6 .

\section{c. Impact on winter SST}

The influence of salinity on upper-ocean temperature is more striking in the wintertime when the sea surface is cooled and the subsurface layer warms, hence forming a subsurface inversion. For these differences we consider two effects: the shallower ML and the wintertime surface cooling. Advection also can be an important element (Thadathil et al. 2002) but, since we are averaging over the entire bay, advection within the bay could be a less decisive factor and the process reduces to a nearly one-dimensional balance between the surface heat flux and oceanic vertical mixing (Rao and Sivakumar 2000).

Figure 11b illustrates the reduction in SST in our model in response to surface freshening. Large cooling occurs over the entire bay and the SEAS, while the northwestern Arabian Sea becomes warmer. The maximum SST decrease in SR, up to $3^{\circ} \mathrm{C}$, is found in the northernmost bay. The area-averaged DJF cooling is $1.1^{\circ} \mathrm{C}$ in $\mathrm{BoB}$ and $0.3^{\circ} \mathrm{C}$ in SEAS. A comparison between the difference in BLT in Fig. 10 and SST in Figs. 11a,b 

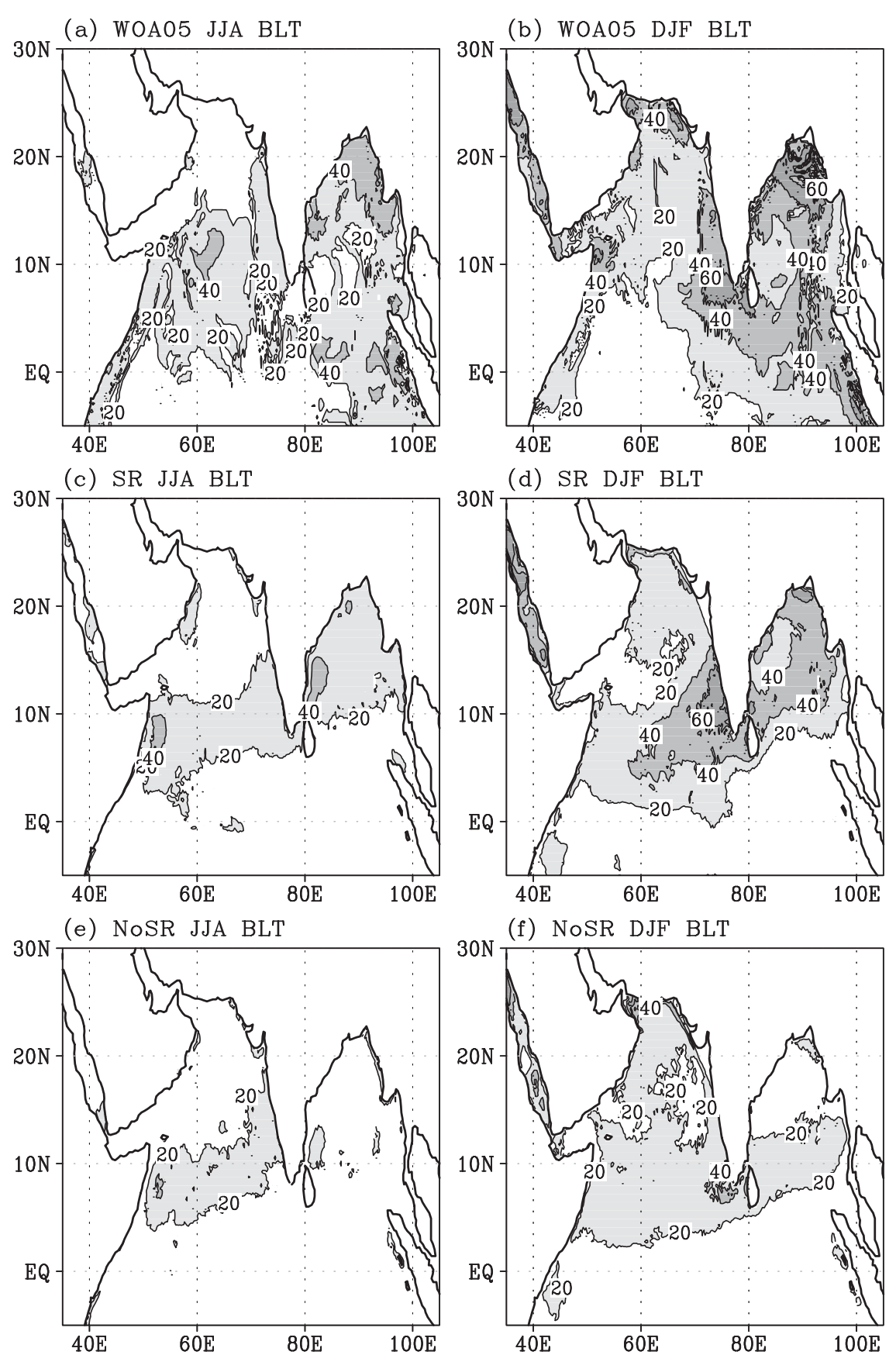

FIG. 10. Twelve-year (1993-2004) averaged barrier layer thickness estimated from the WOA05 in (a) JJA and (b) DJF, SR in (c) JJA and (d) DJF, and NoSR in (e) JJA and (f) DJF. The contour intervals are $20 \mathrm{~m}$; values greater than $20 \mathrm{~m}$ shaded.

indicates that the spatial patterns of changes in two quantities are much more coherent in winter than in summer, which again lends support to the argument that salinity plays a more important role in regulating SSTs in winter in the current model.

Figures $12 \mathrm{~b}, \mathrm{~d}$ show that the wintertime mean MLD over $\mathrm{BoB}$ is about $15-25 \mathrm{~m}$. The $\mathrm{ML}$ is shallower by
$25 \mathrm{~m}$ in SR than in NoSR (Han et al. 2001; HM01). A shallow ML with the river flux limits the surface cooling effects within a thin layer during the winter, resulting in an SST decrease. Figure 8 showed that DJF climatological net heat flux in SR (NoSR) is $-25(-52) \mathrm{W} \mathrm{m}^{-2}-$ both providing a net surface cooling. The reduction of SST in SR occurs despite the reduced net cooling 
(a) JJA SST: SR-NOSR

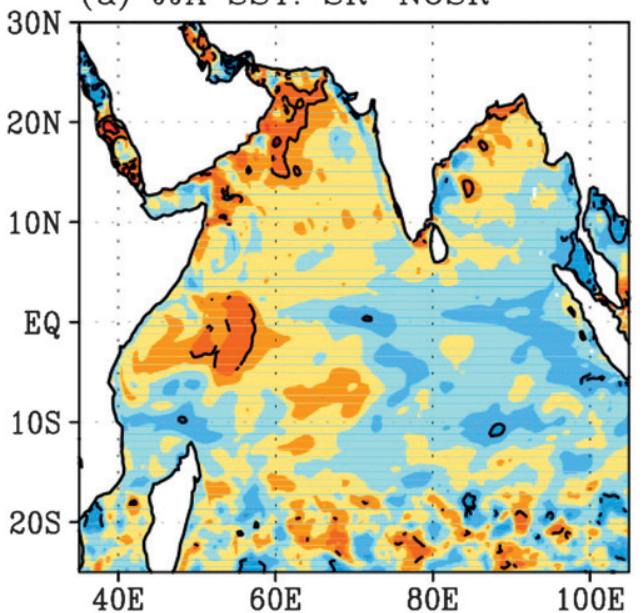

(c) JJA RAIN,WIND: SR-NoSR

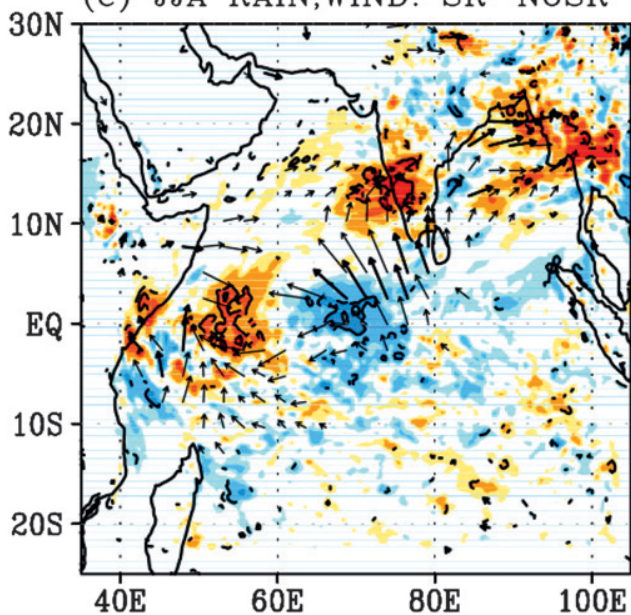

(b) DJF SST:SR-NoSR

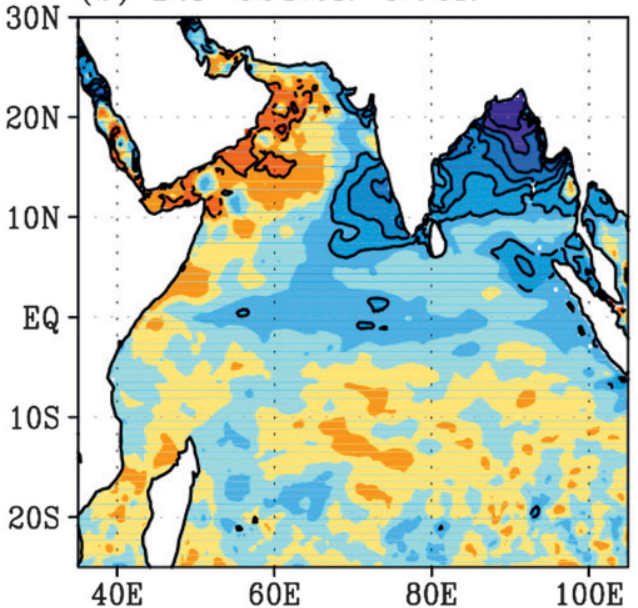

(d) DJF RAIN,WIND: SR-NoSR

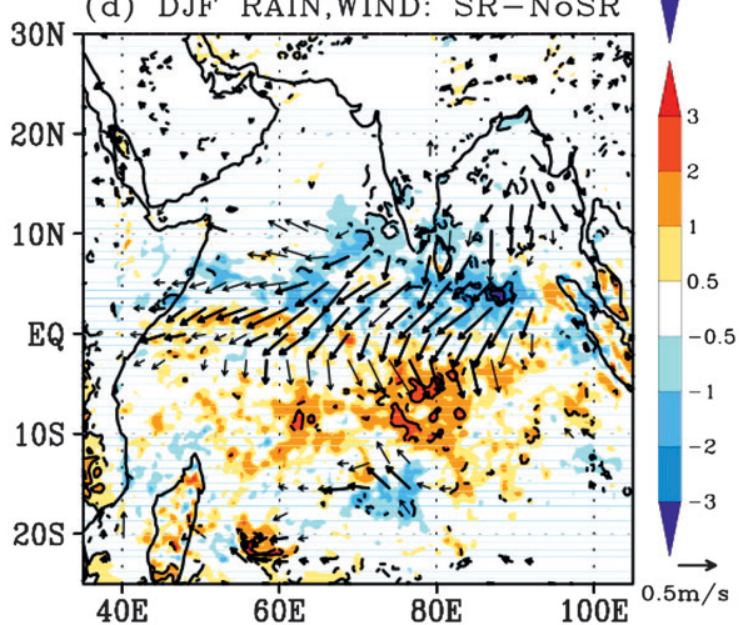

FIG. 11. Changes (SR - NoSR) in (top) SST $\left({ }^{\circ} \mathrm{C}\right)$ and (bottom) rainfall $\left(\mathrm{mm} \mathrm{day}^{-1}\right)$ and $10-\mathrm{m}$ wind speed $\left(\mathrm{m} \mathrm{s}^{-1}\right)$, vectors averaged for (left) JJA and (right) DJF from 1993 to 2004. The overlaid black contours denote the region where change is statistically significant at the $90 \%$ confidence level. The reference vector shown in the lower-right corner of the figure applies to both the thin and thick vectors in (c) and (d).

(by reduced evaporative cooling over the cold water), demonstrating that it is an oceanic process that causes the SST cooling.

\section{Atmospheric response to SST changes}

The previous section showed that lowering salinity via SSS relaxation induces small changes in local SST (where added freshwater forcing is large) during the summer, but in winter it leads to a striking basinwide cooling that is spatially coherent with the change in SSS and the BL. The simulated changes in surface winds and rainfall also exhibit a spatial structure more coherent with the underlying SST in winter than in summer. This section discusses the atmospheric response to the change in SST.

Figures 11c,d show the changes in rainfall and 10-m wind fields in JJA and DJF. During the summer mon- soon period, the westerly and the southwesterly winds tend to become stronger toward the Western Ghats (WG) and in the northern BoB and Indochina in SR. The increased wind leads to enhanced precipitation in these regions. The increase in rain could be understood in part owing to the weak increase in SST in the northern Indian Ocean including the BoB. Generally the amplitude and the area of the significant increase in SST are small and confined near the coast. There is a tendency for summertime convection to be intensified over the $\mathrm{BoB}$, but the change is weak in magnitude. Thus, the direct connection between SST change by the BL and consequent summer monsoon rainfall changes in the WG and $\mathrm{BoB}$ is only marginally supported. Change in the summer monsoon precipitation and rainfall may instead be related to significant changes in SST at the equator rather than to the local BL effects in the northern Indian 

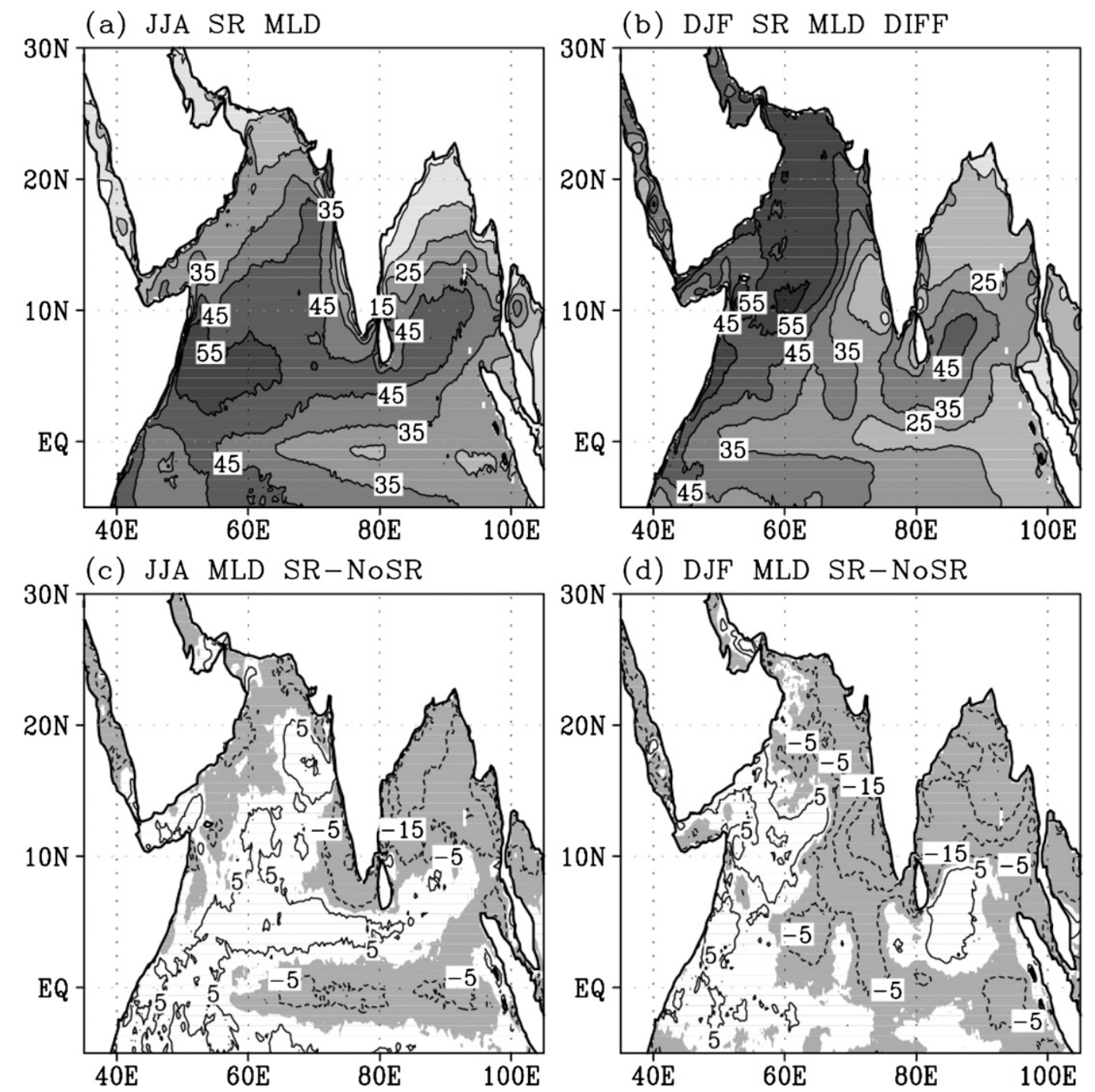

FIG. 12. Twelve-year (1993-2004) averaged mixed layer depth estimated from NoSR averaged for (a) JJA and (b) DJF. MLD differences (SR - NoSR) for (c) JJA and (d) DJF. MLD is defined as the depth at which salinity effects on density variations are equivalent to a $\Delta T=1^{\circ} \mathrm{C}$ decrease of temperature. Contour intervals are $10 \mathrm{~m}$; negative values (shoaling of ML) shaded in gray in (c) and (d).

Ocean. The warming (cooling) at $50^{\circ} \mathrm{E}\left(70^{\circ} \mathrm{E}\right)$ at the equator is associated with a significant increase (decrease) in local precipitation and changes in near-surface convergent (divergent) winds. In particular, the surface divergent flow from $70^{\circ} \mathrm{E}$ appears to contribute to the strengthened southwesterlies and the increased orographic precipitation west of India.

In contrast, the atmospheric response in winter is more coherent with the significant and spatially extensive reduction in SST over the northern Indian Ocean. The decrease of SST shown in SR (Fig. 11b) leads to the formation of near-surface divergent flow originating from the BoB and the SEAS and amplifies the simulated NE monsoon wind (Fig. 11d). This response in simulated wind is consistent with a linear baroclinic response of the troposphere (Gill 1980) to the diabatic cooling associated with the reduced SST. Note that the local response (reduction) in precipitation over the northern Indian Ocean to the sea surface cooling is not remarkable because of the lack of moisture during the winter monsoon period (Table 1). The intensified northeasterly wind, however, tends to reach far southward beyond the northern Indian Ocean, causing a nonlocal response in the atmosphere. The intensified northeasterly wind leads to a surface divergence over the broad region at $5^{\circ} \mathrm{N}$, causing a significant reduction in convection and rainfall of $1-2 \mathrm{~mm} \mathrm{day}^{-1}$. Farther to the south, it intensifies the ITCZ convection. Thus the large-scale atmospheric 
response to the changes in SST due to the $\mathrm{BL}$ is to displace the ITCZ southward.

Note that CGCMs typically have large BL biases in the $\mathrm{BoB}$ and the northern Indian Ocean. In particular, in the latest Community Climate System Model (version 3.5 ) the BL is rather weak (J. Mignot 2008, personal communication), and in DJF there is too much precipitation north and near the equator and too little south of the equator at $10^{\circ}-15^{\circ} \mathrm{S}$ (Jochum and Potemra 2008). This suggests that in current GCMs the weak BL physics, among other factors, could be partially responsible for the tropical precipitation biases. By analyzing the BLs in several CGCMs, Breugem et al. (2008) hypothesized a positive BL-SST-ITCZ feedback that maintains model warm and fresh biases in the southeastern equatorial Atlantic Ocean. Within their feedback process, the $\mathrm{BL}$ is an active and dynamic impetus for generating climate anomalies. The results from previous and present studies suggest that it is critical to capture realistic BLs in coupled climate models for improving the simulation and prediction of regional climate variability, including the Indian monsoons.

\section{Summary and discussion}

We have used a high-resolution, regional coupled ocean-atmosphere model to investigate the effect of river water on the seasonal cycle in the Indian Ocean climate. The model mean state exhibits deviations from observations, with biases in thermocline depth, SST, wind, and rainfall. These biases are somewhat similar in magnitude and spatial pattern to those in current CGCMs over the same area [see reviews of the monsoon biases in the Intergovernmental Panel on Climate Change coupled GCMs by Annamalai et al. 2007 and Bollasina and Nigam 2008].

Our initial hypothesis that motivated this study is that the introduction of a freshwater cap in the Bay of Bengal (BoB) would alleviate the summertime cold bias present in the model through the influence of the barrier layer (BL) on mixing SST. To our surprise, there is no significant change in summertime SST in the northern Indian Ocean despite a more realistic oceanic vertical structure due to the freshwater forcing. There is no significant direct response in wind and rainfall during the southwest (SW) monsoon period to the local change in SST over the BoB. However, we find a significant influence of the BL on local SST during boreal winter with a large atmospheric response in the northeast (NE) monsoon.

The main results are summarized as follows: During the SW monsoon period, a large freshwater influx from rivers, modeled here via SSS relaxation, generates a strong halocline in the $\mathrm{BoB}$, leading to the formation of
BLs and suppressing the mixing between surface and subsurface water. With a reduced warming by surface heat flux and the persistent subsurface warming from the previous winter, the summertime temperature profile exhibits a weak inversion as well. Because of the deep isothermal layer, the weakened mixing effect is not sufficient to further raise the SSTs. Overall, the increase in summer SST averaged over the bay is $0.1^{\circ} \mathrm{C}$ (not significant at the $90 \%$ level), except for the coastal regions adjacent to the mouths of major rivers where SST warms up to $0.4^{\circ} \mathrm{C}$. This is qualitatively consistent with the finding from Han et al. (2001) and HM01 who reported greater warming of $0.5^{\circ}-1.0^{\circ} \mathrm{C}$. The SST warming in SR occurs despite the enhanced damping by the evaporative cooling effect and the reduced shortwave radiation flux, indicating that greater warming in forced ocean models underestimates negative atmospheric damping.

The SW monsoon wind somewhat strengthens in the Western Ghats and northern BoB, causing a rainfall increase in the northern Indian Ocean. The insignificant increase in SST in the northern Indian Ocean does not appear to be responsible for the stronger wind and rainfall. Instead, the divergent flows in the equatorial Indian Ocean, in response to changes in SST there, appear to exert the greater atmospheric influence over the northern Indian Ocean.

During the winter monsoon season, the BLT attains its maximum in the $\mathrm{BoB}$, and the mixed layer consequently becomes shallower. The vertical trapping of the wintertime cooling efficiently decrease the SST by an average of $1.1^{\circ} \mathrm{C}$. The SR run exhibits a strong subsurface inversion layer in the BoB (and southeast Arabian Sea, as discussed by Thadathil and Gosh 1992) with amplitudes of $0.8^{\circ} \mathrm{C}$ (Figs. 6 and 7), consistent with observations. Wintertime cooling of SST in the BoB results in nearly no changes in local rainfall and convection because of lack of moisture convection and the cold SST. Instead, the reduced SST in the northern Indian Ocean amplifies the NE monsoon winds through a linear baroclinic response in the atmosphere. This results in a significant reduction of convection and rainfall around at $5^{\circ} \mathrm{N}$ while enhancing it south of the equator. This indicates a possible connection of ocean stratification with the large-scale atmospheric dynamics during the NE monsoon period.

Masson et al. (2005) suggested from a CGCM experiment that there is a link between the spatial structure of the salinity in the SEAS and the onset of the summer monsoon. This led them to hypothesize that the spatial extent of the BL during the premonsoon season could be a useful predictor of the onset of the summer monsoon. Our model results differ in that the BL had no significant 
impact on summer SST and the SW monsoon. Instead we find that the $\mathrm{BL}$ in the $\mathrm{BoB}$ leaves its clear signature on the wintertime SST and subsequently induces largescale adjustments in convection and rainfall across the equator during the winter monsoon. The importance of understanding the $\mathrm{BL}$ dynamics in the $\mathrm{BoB}$ in winter is further supported by the fact that the simulated monsoon response is not limited to the BoB but extends to the ITCZ and far into the Southern Hemisphere.

Further studies are necessary to determine the detailed structure of this remote atmospheric response and assess its potential impacts on climate. There is a clear need for efforts in understanding the performances of coupled GCMs in reproducing the observed BLs (Kara et al. 2003; DMLC07) in the Indian Ocean. The results of Breugem et al. (2008) in the Atlantic suggest that errors in the BL can cause climate biases through multiple feedback processes in coupled climate models (Lin 2007). A better assessment of the impact of BLs on climate requires an intercomparison exercise using the results from those climate models with and without the salinity and BL effects. These kinds of studies will help determine the extent to which common biases in the climate models can be attributed to BL errors. It will also help detect common and robust features of the sensitivity of the regional climate system to the BLs. Such research will greatly improve our understanding on the potential role of the salinity and the BL in large-scale climate variability, including the Indian monsoon.

Acknowledgments. HS acknowledges the NOAA Climate and Global Change Postdoctoral Fellowship Program, administered by the University Corporation for atmospheric Research. SPX thanks support from the NSF and Japan Agency for Marine-Earth Science and Technology. We thank three anonymous reviewers for their comments and suggestions, which substantially improved the quality of the manuscript. We acknowledge the Center for Observations, Modeling and Prediction at Scripps (COMPAS) for providing the required computer resources for the coupled model simulation. HS thanks M. Kanamitsu, K. Yoshimura, N. Schneider, H. Annamalai, and Z. Yu for their stimulating discussions and comments. NCEP Reanalysis 2 data and NOAA OI SST analysis were provided by the NOAA/OAR/ESRL PSD, Boulder, Colorado, from their Web site at http:// www.cdc.noaa.gov. The GPCP and the CMAP precipitation data were obtained from NCAR Climate Analysis Section Data Catalog at http://www.cgd.ucar.edu/cas/ catalog. The TRMM 3B43_V6 rainfall data were obtained from http://disc.sci.gsfc.nasa.gov. The global MLD/ BLT climatology dataset was provided from http://www. locean-ipsl.upmc.fr/ cdblod.

\section{REFERENCES}

Adler, R. F., and Coauthors, 2003: The Version-2 Global Precipitation Climatology Project (GPCP) monthly precipitation analysis (1979-present). J. Hydrometeor., 4, 1147-1167.

Annamalai, H., R. Murtugudde, J. Potemra, S. P. Xie, P. Liu, and B. Wang, 2003: Coupled dynamics over the Indian Ocean: Spring initiation of the zonal mode. Deep-Sea Res. II, 50, 2305-2330.

_ monsoon and its relationship with ENSO in the IPCC AR4 simulations. J. Climate, 20, 1071-1092.

Antonov, J. I., R. A. Locarnini, T. P. Boyer, A. V. Mishonov, and H. E. Garcia, 2006: Salinity. Vol. 2, World Ocean Atlas 2005, NOAA Atlas NESDIS 62, $182 \mathrm{pp}$.

Behera, S. K., R. Krishnan, and T. Yamagata, 1999: Unusual ocean-atmosphere conditions in the tropical Indian Ocean during 1994. Geophys. Res. Lett., 26, 3001-3004.

Bhat, G. S., and Coauthors, 2001: BOBMEX: The Bay of Bengal Monsoon Experiment. Bull. Amer. Meteor. Soc., 82, 2217-2243.

Bollasina, M., and S. Nigam, 2008: Indian Ocean SST, evaporation, and precipitation during the South Asian summer monsoon in IPCC-AR4 coupled simulations. Climate Dyn., doi:10.1007/ s00382-008-0477-4.

Breugem, W.-P., P. Chang, C. J. Jang, J. Mignot, and W. Hazeleger, 2008: Barrier layers and tropical Atlantic SST biases in coupled GCMs. Tellus, 60, 885-897.

da Silva, A. M., C. Young-Molling, and S. Levitus, 1994: Atlas of surface marine data 1994. NOAA Atlas NESDIS 6-110, 83 pp.

de Boyer Montégut, C., J. Mignot, A. Lazar, and S. Cravatte, 2007: Control of salinity on the mixed layer depth in the world ocean: 1. General description. J. Geophys. Res., 112, C06011, doi:10.1029/2006JC003953.

Durand, F., S. R. Shetye, J. Vialard, D. Shankar, S. S. C. Shenoi, C. Ethe, and G. Madec, 2004: Impact of temperature inversions on SST evolution in the southeastern Arabian Sea during the pre-summer monsoon season. Geophys. Res. Lett., 31, L01305, doi:10.1029/2003GL018906.

Gadgil, S., P. V. Joseph, and N. V. Joshi, 1984: Ocean-atmosphere coupling over monsoon regions. Nature, 312, 141-143.

Gill, A., 1980: Some simple solutions for heat-induced tropical circulation. Quart. J. Roy. Meteor. Soc., 106, 447-462.

Godfrey, J. S., and E. J. Lindstrom, 1989: The heat budget of the equatorial west Pacific surface mixed layer. J. Geophys. Res., 94 (C6), 8007-8017.

Haidvogel, D. B., H. G. Arango, K. Hedstrom, A. Beckmann, P. Malanotte-Rizzoli, and A. F. Shchepetkin, 2000: Model evaluation experiments in the North Atlantic Basin: Simulations in nonlinear terrain-following coordinates. Dyn. Atmos. Oceans, 32, 239-281.

Han, W., and J. P. McCreary Jr., 2001: Modeling salinity distributions in the Indian Ocean. J. Geophys. Res., 106 (C1), 859-878.

,,-- and K. E. Kohler, 2001: Influence of precipitation minus evaporation and Bay of Bengal rivers on dynamics, thermodynamics, and mixed layer physics in the upper Indian Ocean. J. Geophys. Res., 106 (C4), 6895-6916.

Harenduprakash, L. L., and A. K. Mitra, 1988: Vertical turbulent mass flux below the sea surface and air-sea interaction: Monsoon region of the Indian Ocean. Deep-Sea Res. I, 43, 1423-1451.

Hastenrath, S., and P. J. Lamb, 1979: The Oceanic Heat Budget. Vol. 2, Climatic Atlas of the Indian Ocean, University of Wisconsin Press, 110 pp.

Howden, S. D., and R. Murtugudde, 2001: Effects of river inputs into the Bay of Bengal. J. Geophys. Res., 106 (C9), 19 825-19 843. 
Huffman, G. J., and Coauthors, 2007: The TRMM Multisatellite Precipitation Analysis (TMPA): Quasi-global, multiyear, combined-sensor precipitation estimates at fine scale. $J$. Hydrometeor., 8, 38-55.

Izumo, T., C. de Boyer Montégut, J. J. Luo, S. K. Behera, S. Masson, and T. Yamagata, 2008: The role of the western Arabian Sea upwelling in Indian monsoon rainfall variability. J. Climate, 21, 5603-5623.

Jochum, M., and J. T. Potemra, 2008: Sensitivity of tropical rainfall to Banda Sea diffusivity in the Community Climate System Model. J. Climate, 21, 6445-6454.

Joseph, P. V., 1990: Monsoon variability in relation to equatorial trough activity over India and west Pacific Oceans. Mausam (New Delhi), 41, 291-296.

Juang, H.-M. H., and M. Kanamitsu, 1994: The NMC nested regional spectral model. Mon. Wea. Rev., 122, 3-26.

Kanamaru, H., and M. Kanamitsu, 2007: Scale-selective bias correction in a downscaling of global analysis using a regional model. Mon. Wea. Rev., 135, 334-350.

Kanamitsu, M., W. Ebisuzaki, J. Woollen, S.-K. Yang, J. J. Hnilo, M. Fiorino, and G. L. Potter, 2002: NCEP-DOE AMIP-II Reanalysis (R-2). Bull. Amer. Meteor. Soc., 83, 1631-1643.

Kara, A. B., P. A. Rochford, and H. E. Hurlburt, 2000: Mixed layer depth variability and barrier layer formation over the North Pacific Ocean. J. Geophys. Res., 105 (C7), 16 783-16 801.

- _ — and - 2003: Mixed layer depth variability over the global ocean. J. Geophys. Res., 108, 3079, doi:10.1029/ 2000JC000736.

Krishnamurti, T., D. Oosterhof, and A. Mehta, 1988: Air-sea interaction on the time scale of 30 to 50 days. J. Atmos. Sci., $\mathbf{4 5}$, 1304-1322.

Kurian, J., and P. N. Vinayachandran, 2007: Mechanisms of formation of the Arabian Sea mini warm pool in a high-resolution Ocean General Circulation Model. J. Geophys. Res., 112, C05009, doi:10.1029/2006JC003631.

Large, W. G., J. C. McWilliams, and S. C. Doney, 1994: Oceanic vertical mixing: A review and a model with a nonlocal boundary layer parameterization. Rev. Geophys., 32, 363-403.

Levitus, S., 1982: Climatological atlas of the Word Ocean. NOAA Professional Paper 13, NOAA, 173 pp.

Lin, J.-L., 2007: The double-ITCZ problem in IPCC AR4 coupled GCMs: Ocean-atmosphere feedback analysis. J. Climate, 20, 4497-4525.

Locarnini, R. A., A. V. Mishonov, J. I. Antonov, T. P. Boyer, and H. E. Garcia, 2006: Temperature. Vol. 1, World Ocean Atlas 2005, NOAA Atlas NESDIS 61, 182 pp.

Lukas, R., and E. Lindstrom, 1991: The mixed layer of the western equatorial Pacific. J. Geophys. Res., 96 (Suppl.), 3343-3357.

Masson, S., P. Delecluse, J.-P. Boulanger, and C. Menkes, 2002: A model study of the seasonal variability and formation mechanisms of the barrier layer in the eastern equatorial Indian Ocean. J. Geophys. Res., 107, 8017, doi:10.1029/2001JC000832.

_ - and Coauthors, 2005: Impact of barrier layer on winter-spring variability of the southeastern Arabian Sea. Geophys. Res. Lett., 32, L07703, doi:10.1029/2004GL021980.

Mignot, J., C. de Boyer Montégut, A. Lazar, and S. Cravatte, 2007: Control of salinity on the mixed layer depth in the world ocean: 2. Tropical areas. J. Geophys. Res., 112, C10010, doi:10.1029/2006JC003954.

Murtugudde, R., and A. J. Busalacchi, 1998: Salinity effects in a tropical ocean model. J. Geophys. Res., 103 (C2), 3283-3300. , and _- 1999: Interannual variability of the dynamics and thermodynamics of the Indian Ocean. J. Climate, 12, 2300-2326.
_- J. Beauchamp, C. McClain, M. Lewis, and A. Busalacchi, 2002: Effects of penetrative radiation on the upper tropical ocean circulation. J. Climate, 15, 470-486.

—- R. Seager, and P. Thoppil, 2007: Arabian Sea response to monsoon variations. Paleoocenography, 22, PA4217, doi:10.1029/2007PA001467.

Murty, V. S. N., Y. V. B. Sarma, D. P. Rao, and C. S. Murty, 1992: Water characteristics, mixing and circulation in the Bay of Bengal during southwest monsoon. J. Mar. Res., 50, 207-228.

Paulson, C. A., and J. J. Simpson, 1977: Irradiance measurements in the upper ocean. J. Phys. Oceanogr., 7, 952-956.

Prasad, T. G., 1977: Annual and seasonal mean buoyancy fluxes for the tropical Indian Ocean. Curr. Sci., 73, 667-674.

Rao, R. R., and R. Sivakumar, 1999: On the possible mechanisms of the evolution of a mini-warm pool during the pre-summer monsoon season and the genesis of the onset vortex in the SouthEastern Arabian Sea. Quart. J. Roy. Meteor. Soc., 125, 787-809. , and - 2000: Seasonal variability of near-surface thermal structure and heat budget of the mixed layer of the tropical Indian Ocean from a new global ocean temperature climatology. J. Geophys. Res., 105 (C1), 985-1015.

$\longrightarrow$, and _ 2003: Seasonal variability of sea surface salinity and salt budget of the mixed layer of the north Indian Ocean. J. Geophys. Res., 108, 3009, doi:10.1029/2001JC000907.

Reynolds, R. W., N. A. Rayner, T. M. Smith, D. C. Stokes, and W. Wang, 2002: An improved in situ and satellite SST analysis for climate. J. Climate, 15, 1609-1625.

Saji, N. H., B. N. Goswani, P. N. Vinayacjandran, and T. Yamagata, 1999: A dipole mode in the tropical Indian Ocean. Nature, 401, 360-363.

_ , S.-P. Xie, and T. Yamagata, 2006: Tropical Indian Ocean variability in the IPCC twentieth-century climate simulations. J. Climate, 19, 4397-4441.

Sanilkumar, K., N. Mohankumar, M. Joseph, and R. Rao, 1994: Genesis of meteorological disturbances and thermohaline variability of the upper layers in the head of the Bay of Bengal during Monsoon Trough Boundary Layer Experiment (MONTBLEX-90). Deep-Sea Res. I, 40, 1569-1581.

Schott, F. A., and J. P. McCreary Jr., 2001: The monsoon circulation of the Indian Ocean. Prog. Oceanogr., 51, 1-123.

Seager, R., M. B. Blumenthal, and Y. Kushnir, 1995: An advective atmospheric mixed layer model for ocean modeling purposes: Global simulation of surface heat fluxes. J. Climate, 8, 19511964

Sengupta, D., and M. Ravichandran, 2001: Oscillations of Bay of Bengal sea surface temperature during the 1998 summer monsoon. Geophys. Res. Lett., 28, 2033-2036.

Seo, H., A. J. Miller, and J. O. Roads, 2007: The Scripps Coupled Ocean-Atmosphere Regional (SCOAR) model, with applications in the eastern Pacific sector. J. Climate, 20, 381-402.

,- R. Murtugudde, M. Jochum, and A. J. Miller, 2008: Modeling of mesoscale coupled ocean-atmosphere interaction and its feedback to ocean in the western Arabian Sea. Ocean Modell., 25, 120-131.

Shankar, D., S. R. Shetye, and P. V. Joseph, 2007: Link between convection and meridional gradient of sea surface temperature in the Bay of Bengal. J. Earth Syst. Sci., 116, 385-406.

Shchepetkin, A. F., and J. C. McWilliams, 2005: The regional oceanic modeling system (ROMS): A split-explicit, free-surface, topography-following coordinate ocean model. Ocean Modell., 9, 347-404

Shenoi, S. S. C., D. Shankar, and S. R. Shetye, 1999: On the sea surface temperature high in the Lakshadweep Sea before the 
onset of the southwest monsoon. J. Geophys. Res., 104 (C7), $15703-15712$.

- — , and - 2002: Differences in heat budgets of the nearsurface Arabian Sea and Bay of Bengal: Implications for the summer monsoon. J. Geophys. Res., 107, 3052, doi:10.1029/ 2000JC000679.

Shetye, S. R., A. D. Gouveia, D. Shankar, S. S. C. Shenoi, P. N. Vinayachandran, D. Sundar, G. S. Michael, and G. Nampoothiri, 1996: Hydrography and circulation in the western Bay of Bengal during the northeast monsoon. J. Geophys. Res., 101 (C6), 14 011-14 025.

Shukla, J., 1987: Interannual variability of monsoons. Monsoons, J. S. Fein and P. L. Stephens, Eds., John Wiley, 523-548.

Soman, M. K., and J. M. Slingo, 1997: Sensitivity of Asian summer monsoon to aspects of air-surface-temperature anomalies in the tropical Pacific. Quart. J. Roy. Meteor. Soc., 123, 309-336.

Sprintall, J., and M. Tomczak, 1992: Evidence of the barrier layer in the surface layer of the tropics. J. Geophys. Res., 97 (C5), 7305-7316.

Thadathil, P., and A. K. Gosh, 1992: Surface layer temperature inversion in the Arabian Sea during winter. J. Oceanogr., 48, 293-304.

— , V. V. Gopalakrishna, P. M. Muraleedharan, G. V. Reddy, N. Araligidad, and S. Shenoy, 2002: Surface layer temperature inversion in the Bay of Bengal. Deep-Sea Res. I, 49,1801-1818. , P. M. Muraleedharan, R. R. Rao, Y. K. Somayajulu, G. V. Reddy, and C. Revichandran, 2007: Observed seasonal variability of barrier layer in the Bay of Bengal. J. Geophys. Res., 112, C02009, doi:10.1029/2006JC003651.

Ueda, H., M. Ohba, and S.-P. Xie, 2009: Important factors for the development of the Asian-northwest Pacific summer monsoon. J. Climate, 22, 649-669.

Varkey, M. J., V. S. N. Murty, and A. Suryanarayana, 1996: Physical oceanography of the Bay of Bengal and Andaman Sea. Oceanogr. Mar. Biol., 34, 1-70.
Vecchi, G. A., and D. E. Harrison, 2004: Interannual Indian rainfall variability and Indian Ocean sea surface temperature anomalies. Earth's Climate: The Ocean-Atmosphere Interaction, Geophys. Monogr., Vol. 147, Amer. Geophys. Union, 247-260.

Vialard, J., and P. Delecluse, 1998: An OGCM study for the TOGA decade. Part II: Barrier-layer formation and variability. J. Phys. Oceanogr., 28, 1089-1106.

Vinayachandran, P. N., V. S. Murty, and V. Ramesh Babu, 2002: Observations of barrier layer formation in the Bay of Bengal during summer monsoon. J. Geophys. Res., 107, 8018, doi:10.1029/2001JC000831.

_ - D. Shankar, J. Kurian, F. Durand, and S. S. C. Shenoi, 2007: Arabian Sea mini warm pool and the monsoon onset vortex. Curr. Sci., 93, 203-214.

Wang, B., Q. Ding, X. Fu, I.-S. Kang, K. Jin, J. Shukla, and F. Doblas-Reyes, 2005: Fundamental challenge in simulation and prediction of summer monsoon rainfall. Geophys. Res. Lett., 32, L15711, doi:10.1029/2005GL022734.

Webster, P. J., A. M. Moore, J. P. Loschnigg, and R. R. Leben, 1999: Coupled ocean-atmosphere dynamics in the Indian Ocean during 1997-98. Nature, 401, 356-360.

Xie, P., and P. A. Arkin, 1997: Global precipitation: A 17-year monthly analysis based on gauge observations, satellite estimates, and numerical model outputs. Bull. Amer. Meteor. Soc., 78, 2539-2558.

Xie, S.-P., H. Xu, N. H. Saji, Y. Wang, and W. T. Liu, 2006: Role of narrow mountains in large-scale organization of Asian monsoon convection. J. Climate, 19, 3420-3429.

Yoshimura, K., and M. Kanamitsu, 2008: Dynamical global downscaling of global reanalysis. Mon. Wea. Rev., 136, 2983-2998.

Yu, Z., and J. P. McCreary, 2004: Assessing precipitation products in the Indian Ocean using an ocean model. J. Geophys. Res., 109, C05013, doi:10.1029/2003JC002106.

Zhou, L., and R. Murtugudde, 2009: Ocean-atmosphere coupling on different temporal and spatial scales. J. Atmos. Sci., 66, 1834-1844. 